\title{
Functional Characterization of an Aspergillus fumigatus Calcium Transporter (PmcA) that Is Essential for Fungal Infection
}

\author{
Taísa Magnani Dinamarco ${ }^{2}$, Fernanda Zanolli Freitas ${ }^{6}$, Ricardo S. Almeida ${ }^{5}$, Neil Andrew Brown ${ }^{2}$, Thaila \\ Fernanda dos Reis ${ }^{2}$, Leandra Naira Zambelli Ramalho ${ }^{4}$, Marcela Savoldi ${ }^{2}$, Maria Helena S. Goldman ${ }^{3}$, \\ Maria Célia Bertolini ${ }^{6}$, Gustavo Henrique Goldman ${ }^{1,2 *}$
}

1 Laboratório Nacional de Ciência e Tecnologia do Bioetanol - CTBE, Campinas, São Paulo, Brazil, 2 Faculdade de Ciências Farmacêuticas de Ribeirão Preto, Universidade de São Paulo, São Paulo, Brazil, 3 Faculdade de Filosofia, Ciências e Letras de Ribeirão Preto, Universidade de São Paulo, São Paulo, Brazil, 4 Faculdade de Medicina de Ribeirão Preto, Universidade de São Paulo, São Paulo, Brazil, 5 Department of Microbiology, University of Londrina, Londrina, Paraná, Brazil, 6 Instituto de Química, UNESP, Araraquara, São Paulo, Brazil

\begin{abstract}
Aspergillus fumigatus is a primary and opportunistic pathogen, as well as a major allergen, of mammals. The $\mathrm{Ca}^{+2}$-calcineurin pathway affects virulence, morphogenesis and antifungal drug action in A. fumigatus. Here, we investigated three components of the $A$. fumigatus $\mathrm{Ca}^{+2}$-calcineurin pathway, $p m c A,-B$, and $-C$, which encode calcium transporters. We demonstrated that CrzA can directly control the mRNA accumulation of the pmcA-C genes by binding to their promoter regions. CrzA-binding experiments suggested that the $5^{\prime}$-CACAGCCAC-3' and $5^{\prime}$-CCCTGCCCC-3' sequences upstream of pmcA and pmcC genes, respectively, are possible calcineurin-dependent response elements (CDREs)-like consensus motifs. Null mutants were constructed for $p m c A$ and $-B$ and a conditional mutant for $p m c C$ demonstrating $p m c C$ is an essential gene. The $\triangle p m c A$ and $\triangle p m c B$ mutants were more sensitive to calcium and resistant to manganese and cyclosporin was able to modulate the sensitivity or resistance of these mutants to these salts, supporting the interaction between calcineurin and the function of these transporters. The pmcA-C genes have decreased mRNA abundance into the alveoli in the $\triangle$ calA and $\triangle c r z A$ mutant strains. However, only the A. fumigatus $\triangle p m c A$ was avirulent in the murine model of invasive pulmonary aspergillosis.
\end{abstract}

Citation: Dinamarco TM, Freitas FZ, Almeida RS, Brown NA, dos Reis TF, et al. (2012) Functional Characterization of an Aspergillus fumigatus Calcium Transporter (PmcA) that Is Essential for Fungal Infection. PLoS ONE 7(5): e37591. doi:10.1371/journal.pone.0037591

Editor: Yong-Sun Bahn, Yonsei University, Republic of Korea

Received March 7, 2012; Accepted April 22, 2012; Published May 23, 2012

Copyright: (C) 2012 Dinamarco et al. This is an open-access article distributed under the terms of the Creative Commons Attribution License, which permits unrestricted use, distribution, and reproduction in any medium, provided the original author and source are credited.

Funding: This research was supported by the Fundação de Amparo à Pesquisa do Estado de São Paulo (FAPESP), and Conselho Nacional de Desenvolvimento Científico e Tecnológico (CNPq), Brazil. The funders had no role in study design, data collection and analysis, decision to publish, or preparation of the manuscript.

Competing Interests: Gustavo Henrique Goldman is currently serving as an editor for PLoS ONE. This does not alter the authors' adherence to all the PLoS ONE policies on sharing data and materials.

*E-mail: ggoldman@usp.br

\section{Introduction}

Calcium ions are extremely important for signal transduction. Two important calcium mediators in the eukaryotic cell are calmodulin and the phosphatase calcineurin [1,2]. Calcineurin is a heterodimeric protein composed by a catalytic subunit $\mathrm{A}$ and a regulatory subunit B [1]. In fungi, calcineurin plays an important role in the control of cell morphology and virulence $[1,2,3,4]$. The main mode of action of calcineurin is through the dephosphorylation of the transcription factor Crzlp [5]. Calcineurin dephosphorylates Crzlp upon an increase in cytosolic calcium, allowing its nuclear translocation [5,6]. CRZ1 deficient mutants display hypersensitivity to chloride and chitosan, a defective transcriptional response to alkaline stress and defects in cellular morphology and mating $[5,7,8,9]$. Inactivated Schizosaccharomyces pombe CRZ1 mutants ( $\triangle$ przl) are hypersensitive to calcium and have decreased transcription of the Pmcl $\mathrm{Ca}^{+2}$ pump [10]. C. albicans homozygotes crz $1 \Delta / \Delta$ display moderately attenuated virulence and sensitive to calcium, lithium, manganese, and sodium dodecyl sulfate $[6,11,12]$.
We and others have been characterizing the $\mathrm{Ca}^{+2}$-calcineurin pathway in the human pathogenic fungus $A$. fumigatus [3]. In this fungus calcineurin is need for hyphal extension, branching and conidial architecture. Furthermore, the A. fumigatus $\Delta$ calA mutant strain has decreased fitness in a low dose murine infection, cannot grow in fetal bovine serum (FBS), and is deficient in inorganic phosphate transport $[3,13]$. Three other elements in this pathway were also characterized: (i) the transcription factor CrzA [14,15], (ii) the $\mathrm{R} c n \mathrm{~A} / \mathrm{CbpA}$, belonging to a class of endogenous calcineurin regulators, calcipressins [16,17], and (iii) the Golgi apparatus $\mathrm{Ca}^{+2} / \mathrm{Mn}^{+2}$ P-type ATPase PmrA [16]. CrzA mediates cellular tolerance to increased concentrations of calcium and manganese $[14,15]$. In addition to acute sensitivity to these ions and decreased conidiation, the $\operatorname{crz} A$ null mutant suffers from decreased expression of calcium transporters under high calcium concentrations and a loss of virulence. The last identified component of the pathway in A. fumigatus, PmrA, has been demonstrated to play a role in cation homeostasis and in the cell wall integrity pathway [16]. 
Fungal vacuolar $\mathrm{Ca}^{2+}$ ATPases are involved in removing $\mathrm{Ca}^{2+}$ ions from the cytosol and transporting them to internal stores thus avoiding calcium toxicity [18]). In fungi, the vacuole is a major calcium store and the two main pathways that facilitate the accumulation of $\mathrm{Ca}^{+2}$ into vacuoles are the $\mathrm{Ca}^{+2}$-ATPases and $\mathrm{Ca}^{+2} / \mathrm{H}^{+}$exchangers [18]. In S. cerevisiae, PMC1 is responsible for this process preventing growth inhibition by the activation of calcineurin in the presence of elevated calcium concentrations [19]. Here, we report the molecular characterization of three $A$. fumigatus PMC1 calcium transporter-encoding genes, $p m c A-C$. We demonstrated that CrzA directly controls the $p m c A-C$ mRNA accumulation via binding to their promoter regions. We constructed null mutants for pmcA-B, a conditional mutant for $p m c C$ and investigated the phenotypes/virulence of these deletions in a murine model of invasive pulmonary aspergillosis. We show that $A$. fumigatus pmc $C$ is an essential gene, while $p m c A$ and $p m c B$ are both involved in calcium and manganese metabolism. However, only pmcA had a dramatic impact on $A$. fumigatus virulence and pathogenicity, since $A$. fumigatus $\triangle p m c A$ was avirulent in a murine model of invasive pulmonary aspergillosis.

\section{Results}

\section{Identification of three $A$. fumigatus PMC1 homologues}

The three main calcium transporters responsible for calcium metabolism in S. cerevisiae are PMC1, VCX1, and PMR1 [20]. A phylogenetic analysis was performed in order to learn more about homologues of these transporters and other putative $A$. fumigatus calcium transporters (Figure 1). Previously we observed that the mRNA abundance of two PMC1 orthologous genes, pmcA (Afulg10880) and pmcB (Afu3g10690), which encode calcium transporters, was dependent on CalA and CrzA (Soriani et al., 2008). By using this approach, we have identified an additional PMC1 orthologue, pmcC (Afu7g01030). S. cerevisiae VCX1 encodes a vacuolar antiporter with $\mathrm{Ca}^{+2} / \mathrm{H}^{+}$and $\mathrm{K}^{+} / \mathrm{H}^{+}$exchange activity, which is involved in the control of cytosolic $\mathrm{Ca}^{+2}$ and $\mathrm{K}^{+}$ concentrations [21]. There are four A. fumigatus Vcxlp homologues, Afulg04270 and Afu4g03320 (possibly paralogues), Afu2g07630 and Afu2g05320 (Figure 1). Finally, S. cerevisiae PMR1 encodes a high affinity $\mathrm{Ca}^{+2} / \mathrm{Mn}^{+2}$ P-type ATPase required for $\mathrm{Ca}^{+2}$ and $\mathrm{Mn}^{+2}$ transport into the Golgi [22]. We have identified two A. fumigatus PMR1 homologues, Afu2g05860 and Afu6g06740 (Figure 1). Recently, A. fumigatus pmrA (Afu2g05860) was characterized [16]. The $\Delta p m r A$ mutant strain has increased $\beta$ glucan and chitin content and it is hypersensitive to cell wall inhibitors, but remains virulent. In addition to these three classes of transporters, we also identified homologues for the calcium channel subunit Midl (Afu5g05840), an $\mathrm{H}^{+} / \mathrm{Ca}^{+2}$ exchanger (Afu2g05330), the calcium channel subunit Cchl (Afulg11110), and a calcium permease family membrane transporter (Figure 1).

Here, we concentrate our attention on the molecular characterization of A. fumigatus PMC1 homologues. These three putative proteins showed approximately $45 \%$ identity and $67 \%$ similarity (e-value from $7.0 \mathrm{e}-160$ to $1.4 \mathrm{e}-208$ ) to the $S$. cerevisiae PMC1 homologue. PmcA demonstrates $51 \%$ identity and $63 \%$ similarity with PmcB (e-value 6.9e-271) and 45\% identity and 58\% similarity with PmcC (e-value 4.e-174) while, PmcB and PmcC showed 53\% identity and $66 \%$ similarity (e-value $2.7 \mathrm{e}-276$ ) (for the Clustal aligment of these three proteins, see Supplementary Figure S1). PmcA-C are closely related and probably paralogues (Figure 1). In addition to $p m c A$ and $p m c B$, the $p m c C$ gene also has decreased mRNA abundance in the $\triangle$ calA and $\triangle$ crzA mutant strains, respectively, when exposed in vitro to $\mathrm{CaCl}_{2} 200 \mathrm{mM}$, compared to wild-type $A$. fumigatus [14,17, data not shown]. To address if
CrzA is directly controlling the transcription of $p m c A-C$, we performed Electrophoretic Mobility Shift Assays (EMSA) using purified recombinant GST::CrzA produced in E. coli. Previously, we performed an in silico analysis using MEME (Motif-based sequence analysis tools; http://meme.sdsc.edu/meme4_1_1/ intro.html) to detect the possible presence of a calcineurindependent response elements (CDREs)-like consensus motifs in the promoter regions of 28 A. fumigatus CrzA-dependent genes [17]. By analyzing their promoter regions, 5'-GT[T/G]G[G/C][T/ $\mathrm{A}] \mathrm{GA}[\mathrm{G} / \mathrm{T}]-3^{\prime}$ was defined as the CDRE-consensus sequence for $A$. fumigatus AfCrzA-dependent genes. When the $p m c A-C$ promoter regions (about 500-bp upstream ATG) were scanned for putative CDRE motifs, we were able to identify the $5^{\prime}$ CCCTGCCCG-3' and 5'-CACAGCGAC-3' sequences (at - 156 and -102 bp from the ATG start codon, respectively) in the pmcA and $p m c C$ promoter regions. However, we could not identify any conserved CDRE motif in the $p m c B$ promoter region (Supplementary Figure S2). Three DNA fragments of about 300-bp located upstream the putative ATG initiation codon of pmcA-C genes were used as probes (Supplementary Figure S2). DNAprotein complexes with reduced mobility were observed in the three DNA fragments (Figure 2), however the complexes affinities were different among the three fragments. While $2 \mu \mathrm{g}$ of GST::CrzA were required for the binding of the $p m c C$ probe (Figure 2, lane 16), $1 \mu \mathrm{g}$ of protein was enough to produce strong DNA-protein complexes for the $p m c A$ (Figure 2, lane 2) and $p m c B$ (Figure 2, lane 11) probes. This suggests that CrzA has low affinity to the $p m c C$ promoter.

The complexes specificities were confirmed by addition of unlabelled probes as specific competitors. Addition of 50-fold molar excess of unlabelled probes completely inhibited the complexes formed with $p m c B$ and $p m c C$ DNA fragments. The addition of approximately a 15-fold molar excess of the DNA oligonucleotide (5'-CACAGCGAC-3') inhibited completely the pmc $C$ complex specificity (Figure 2, lane 20). However the complex pmcA-CrzA was only inhibited in the presence of a 30 -fold molar excess of DNA oligonucleotide (5'-CGCTGCCCC-3') containing the CDRE motif used as specific competitor (Figure 2, lane 7). This result suggests a strong CrzA affinity for this DNA fragment. The specificity of the DNA-protein complex was also confirmed by using mutated $p m c A$ and $p m c C$ probes, in which the core sequences were changed by site-directed mutagenesis. We have not investigated a mutated $p m c B$ DNA fragment because we were not able to identify a conserved CDRE motif in this upstream region. We have not observed the formation of any complex by using both mutated DNA fragments as probes (Figure 2, lane 9 for $\mathrm{m} p m c A$ probe and lane 23 for $\mathrm{m} p m c C$ probe). An interesting result was the presence of two complexes exhibiting different molecular masses for $p m c A$ and $p m c B$ probes. We speculate that they may represent complexes with distinct conformational structures. Additional experiments will be necessary to clarify this. Taken together our results suggest that the mRNA accumulation of $p m c A$ $C$ is directly regulated by CrzA.

\section{Construction of the $A$. fumigatus pmcA-C mutants}

To get a greater understanding of the role of $p m c A-C$, we tried to inactivate all three genes (Supplementary Figure S3). However, we were unable to inactivate $p m c C$, suggesting that this is an essential A. fumigatus gene. Thus, we constructed an alcA::pmc $C$ mutant by replacing the endogenous $p m c C$ promoter with the alc $A$ promoter and verified its growth when the alcA promoter was repressed. The alc $A$ promoter is repressed by glucose, derepressed by glycerol and induced to high levels by ethanol or L-threonine [23]. We selected a transformant that when transferred from $16 \mathrm{~h}$ growth in $2 \%$ 


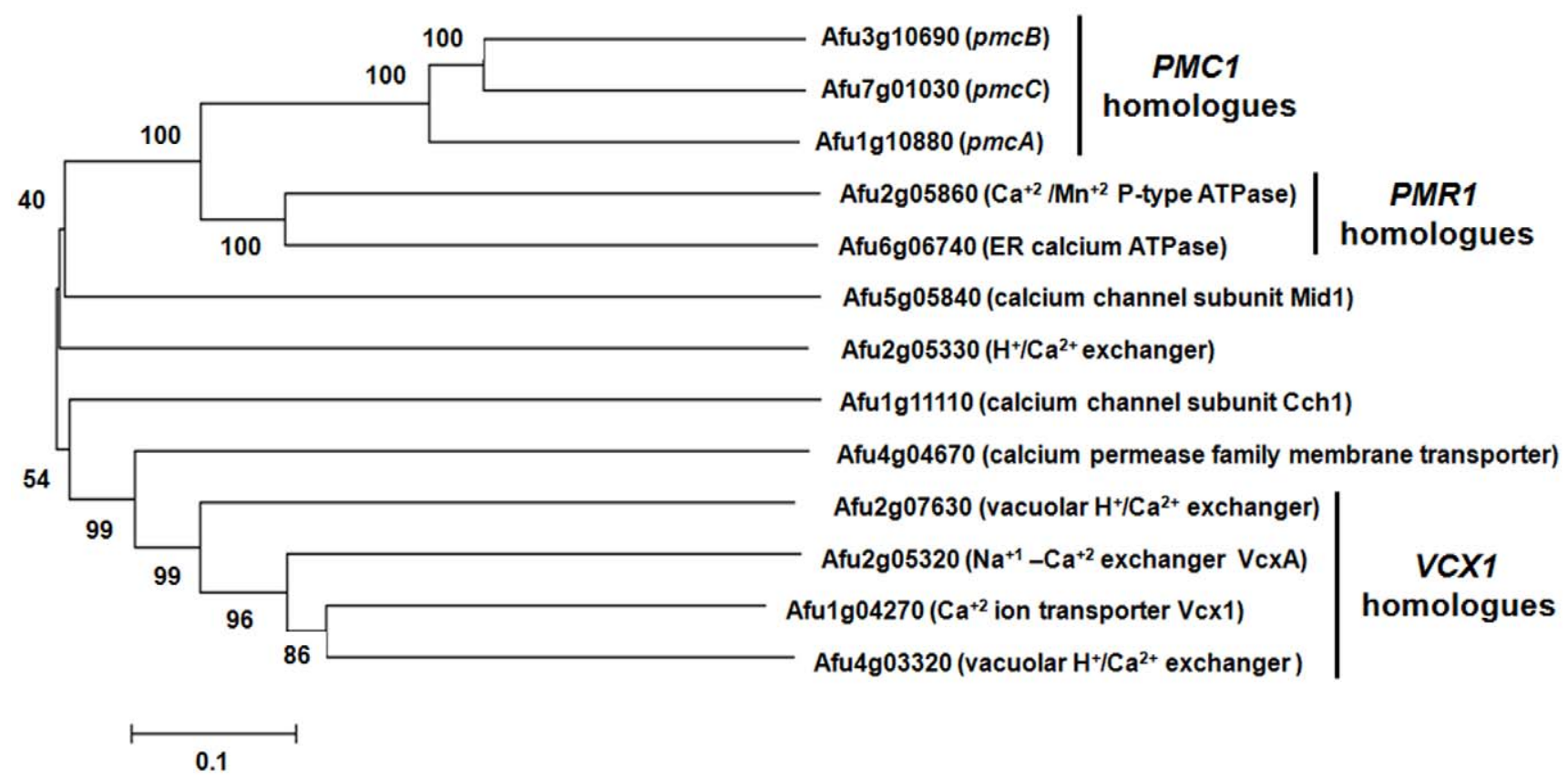

Figure 1. A. fumigatus has three $S$. cerevisiae $P M C 1$ homologues. Phylogram tree and multiple sequence alignment of calcium transporter orthologues were made in CLUSTAL W2 (http//www.ebi.ac.uk/Tools/clustalw2/index.html) using the default parameters. The followings proteins were used for the analysis: Afu3g10690 (pmcB; XP_754550); Afu7g01030 (pmcC; XP_746828); Afu1g10880 (pmcA; XP_752453); Afu2g05860 (calcium/ mangenese P-type ATPase: XP 749715); Afu6g06740 (endoplasmic reticulum calcium ATPase: XP 750567); Afu5g05840 (calcium channel subunit Mid1: XP_754048); Afu2g05330 (vacuolar H+/Ca2+ exchanger: XP_749663); Afu1g11110 (calcium channel subunit Cch1: XP_752476); Afu4g04670 (calcium permease family membrane transporter: XP_746653); Afu2g07630 (vacuolar H+/Ca2+ exchanger: XP_755098); Afu2g05320 (calcium-proton exchanger: XP_749662); Afu1g04270 (calcium ion transporter Vcx1: XP_750174); and Afu4g03320 (similar to vacuolar $\mathrm{H}^{+} / \mathrm{Ca}^{2+}$ exchanger: XP_001481534).

doi:10.1371/journal.pone.0037591.g001

glycerol, as single carbon source, to $2 \%$ glycerol $+100 \mathrm{mM}$ threonine for $6 \mathrm{~h}$, the mRNA accumulation of $p m c C$ was approximately 15-fold higher than when grown in the presence of $4 \%$ glucose (Figure 3A). The repression of alcA by growing the alcA::pmc $C$ mutant strain in the presence of $4 \%$ glucose decreased colony diameter dramatically (Figure 3B). In contrast, both wildtype and alcA::pmcC strains demonstrated similar radial diameter when grown in $2 \%$ glycerol (Figure 3B). Interestingly, pmc C overexpression also decreased the colony diameter size when compared to the wild-type strain, suggesting increased PmcC activity causes some metabolic disturbance that affects growth (Figure 3B). These results strongly indicate $p m c C$ is an essential $A$. fumigatus gene.

We also compared the absolute levels of mRNA abundance among $p m c A,-B$, and $-C$ when the $A$. fumigatus wild-type, $\Delta p m c A$ and $\triangle p m c B$ mutant strains were exposed to $200 \mathrm{mM} \mathrm{CaCl}{ }_{2}$ (Figure 4). Upon exposure of wild-type $A$. fumigatus to calcium, $p m c B$ mRNA levels were higher than $p m c A$ and $p m c C$, while $p m c A$ levels were higher than $p m c C$ (Figures $4 \mathrm{~A}-\mathrm{C}$ ). The number of normalized $p m c A$ and $p m c C$ transcripts in the $\triangle p m c B$ and $\triangle p m c A$ mutant strains, respectively, were not different from the wild-type strain (Figures 4A and B), suggesting the absence of either $p m c B$ or $p m c A$ does not considerably affect the mRNA abundance of $p m c A$

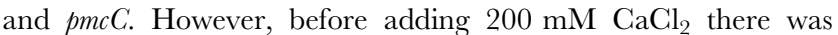
approximately six times more $p m c B$ transcripts in the $\triangle p m c A$ than in the wild-type strain (Figure $4 \mathrm{~B}$ ). Interestingly, the $p m c C$ mRNA levels are reduced upon $\mathrm{CaCl}_{2}$ exposure in both $\triangle p m c B$ and $\triangle p m c A$ mutant strains. These results suggest that there is compensation in the mRNA accumulation of $p m c B$ in the $\triangle p m c A$ mutant strain and $p m c C$ mRNA accumulation is dependent on $p m c A$ and $p m c B$. Upon calcium exposure, down-regulation or overexpression of $p m c C$ had no effect on $p m c A$ or $p m c B$ mRNA accumulation (data nor shown).

Next, we characterized the phenotype of $\triangle p m c A$ and $\triangle p m c B$ by growing these strains in different culture media in the presence and absence of cyclosporin A (CsA). This immunosuppressive drug inhibits calcineurin signaling by forming a complex with the immunophilin cyclophilin which then inhibits calcineurin [24]. In addition, since the $\triangle \operatorname{cr} z A$ mutant is also sensitive to $\mathrm{MnCl}_{2}$ (Soriani et al., 2008), we decided to investigate a possible influence of $p m c A$ $B$ on this phenotype. Curiously, the $\triangle p m c A$ mutant strain demonstrated different behavior in complete (YAG) and minimal media (MM) (Figure 5A). It showed reduced radial growth rate in complete medium when compared to the wild-type strain, but this reduction in growth was not suppressed by cyclosporin $25 \mathrm{ng} / \mathrm{ml}$ (Figures 5A). The $\triangle p m c A$ mutant strain was sensitive to $\mathrm{CaCl}_{2}$ $500 \mathrm{mM}$ and showed increased sensitivity in YAG and MM, compared to both the wild-type and other mutant strains, when cyclosporin $25 \mathrm{ng} / \mathrm{ml}$ was added (Figure $5 \mathrm{~B}$ ). The $\triangle p m c A$ mutant strain was resistant to $\mathrm{MnCl}_{2} 25 \mathrm{mM}$ in both YAG and $\mathrm{MM}$ media, however cyclosporin suppressed $\triangle p m c A$ resistance in YAG and wild-type sensitivity in MM (Figure $5 \mathrm{C}$ ). The $\triangle p m c B$ mutant strain had about the same radial diameter than the wild-type strain in both MM and YAG media (Figure 6A), but it was much more sensitive to $\mathrm{CaCl}_{2}$ in YAG and showed increased sensitivity when grown in the presence of cyclosporin (Figure 6B). However, in $\mathrm{MM}+500 \mathrm{mM} \mathrm{CaCl}_{2}$ the $\Delta p m c B$ mutant strain has the same radial diameter as the wild-type strain (Figure 6B). In addition, the $\triangle p m c B$ mutant strain was more resistant to YAG+25 mM MnCl 2 than the wild-type strain (Figure 6C), but this resistance was suppressed in the presence of cyclosporin (Figure 6C). The same growth was observed for both wild-type and $\triangle p m c B$ when grown in 

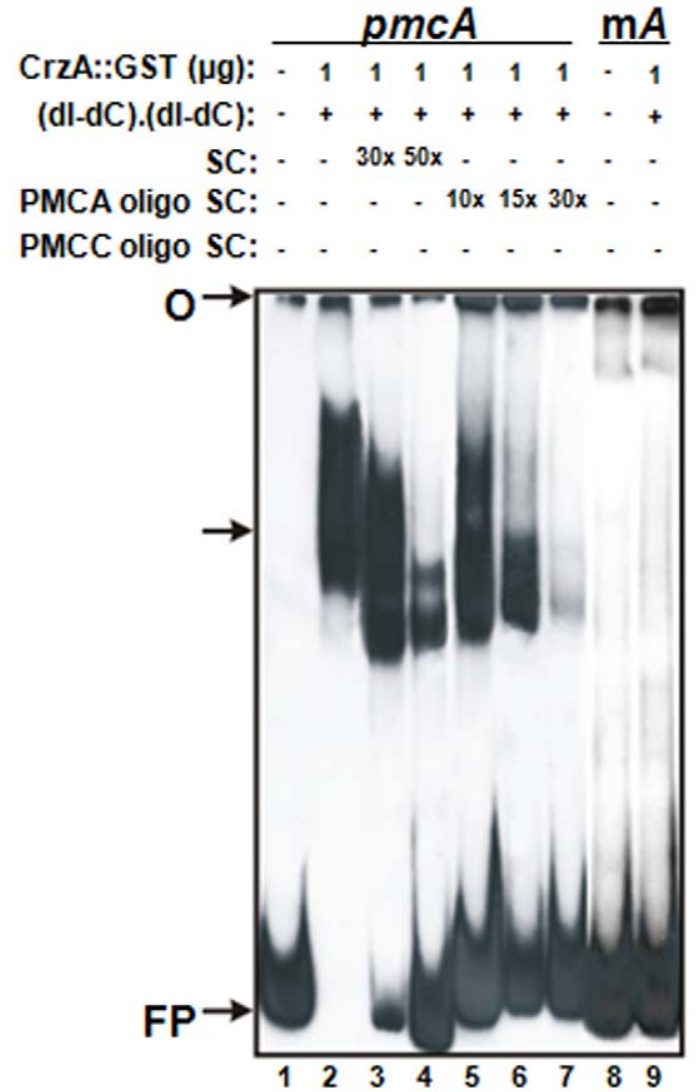
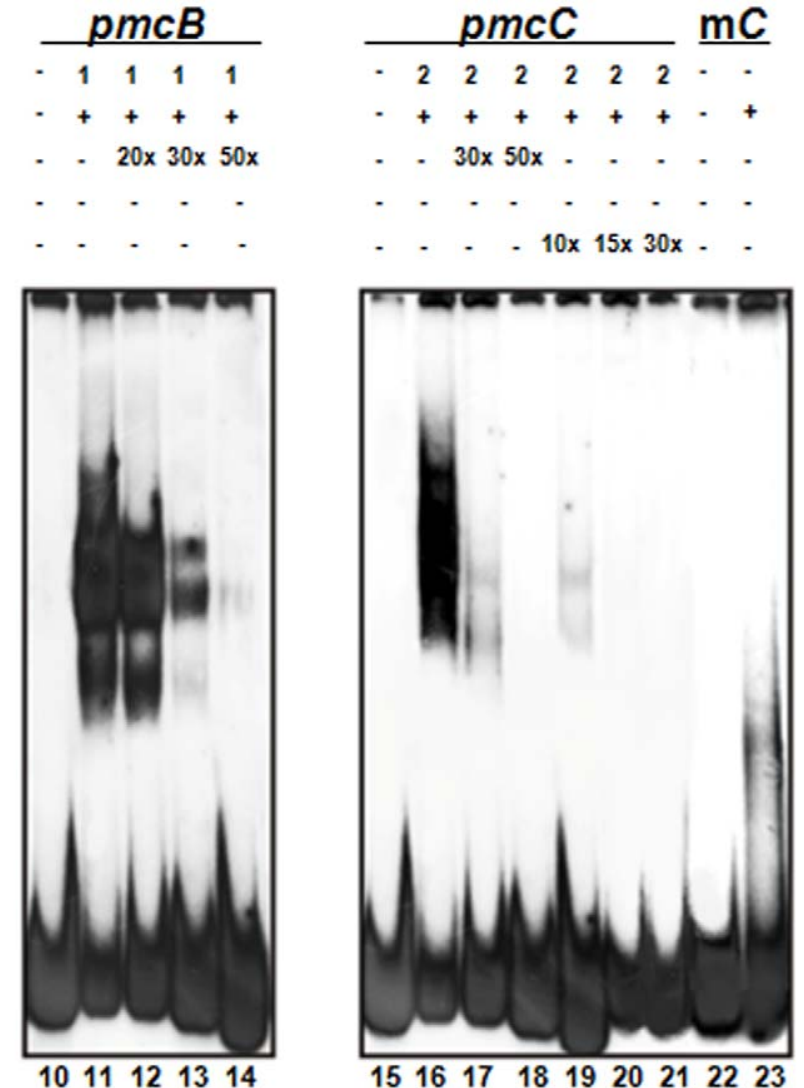

Figure 2. Binding of GST::CrzA recombinant protein to $p m c A-C$ promoters. Gel shift analysis was performed using three DNA fragments of pmcA, pmcB and pmcC promoters as probes and $1.0 \mu \mathrm{g}$ to $2.0 \mu \mathrm{g}$ of the CrzA::GST recombinant protein. Lanes 1 to 7 , pmcA probe; lane 1 , no protein added. Lanes 8 and 9, mutated pmcA probe. Lanes 10 to 14, pmcB probe; lane 10, no protein added. Lanes 11 to 14 , fragments from $p m c B$ probe. Lanes 15 to 23, pmcC probe; lane 15, no protein added. Lanes 22 and 23, mutated pmcC probe. O, gel origin; SC, specific competitor; FP, free probe. The arrow indicates the CrzA::GST-DNA complexes. doi:10.1371/journal.pone.0037591.g002

$\mathrm{MM}+25 \mathrm{mM} \mathrm{MnCl}_{2}$ (Figure 6C). Both the $\triangle p m c A:: p m c A^{+}$and $\triangle p m c B:: p m c B^{+}$showed the same phenotype as the wild-type strain, strongly indicating that the null phenotypes observed for both genes were only due to the introduction of these mutations in the corresponding strains (Figures 5 and 6).

Since the $\triangle p m c A$ and $\triangle p m c B$ strains were calcium-sensitive but manganese-resistant, we decide to investigate the mRNA abundance of each $p m c$ gene when the wild-type, $\triangle p m c A$ and $\Delta p m c B$ mutant strains were exposed to a short pulse of $\mathrm{MnCl}_{2}$ (Figure 7). All three genes showed increased mRNA abundance in the presence of $\mathrm{MnCl}_{2}$ ( $p m c A$ and $p m c B$ have 2.5- and 2.0-fold more transcripts after 10 minutes; Figures $7 \mathrm{~A}$ and $\mathrm{B}$ ), however the highest induction was observed for $p m c C$ that showed a 30- and 3.7-fold increase in transcripts after 10 and 30 minutes, respectively (Figure 7G). Nevertheless, like observed for calcium induction, the absolute mRNA levels of $p m c C$ are the lowest among all the three genes (Figure 7). The pmcA mRNA levels in the $\triangle p m c B$ mutant strain exposed to $\mathrm{MnCl}_{2}$ were about the same as the wild-type strain (Figure 7A). When the $\triangle p m c A$ mutant strain was exposed to $\mathrm{MnCl}_{2}$, the mRNA levels of $p m c B$ were 2.5-fold higher than the wild-type strain after 10 minutes exposure. Interestingly, the $p m c B$ mRNA levels in this mutant without any $\mathrm{MnCl}_{2}$ exposure (i.e., the control before exposure) were 2.3-fold higher than the wild-type strain (Figure 7B). Finally, there was a decrease in the $p m c C$ mRNA levels after $\triangle p m c A$ and $\triangle p m c B$ mutant strains were exposed to $\mathrm{MnCl}_{2}$ (Figure 7G). Down-regulation or overexpression of $p m c C$ had no effect on $p m c A$ or $p m c B$ mRNA accumulation (data nor shown).

Finally, we evaluated the relative concentration of free calcium in the $A$. fumigatus wild-type, $\triangle p m c A, \triangle p m c B, \triangle p m c A:: p m c A^{+}$, and $\triangle p m c B:: p m c B^{+}$strains by using Fura-2-AM, a highly sensitive dye for rapid measurement of calcium flux in cells (www.invitrogen. com). Fura-2-Am is a fluorescent calcium indicator that can passively diffuse across cell membranes and when inside the cell, the esters are cleaved by intracellular esterases to yield cellimpermeant fluorescent indicator. Upon binding $\mathrm{Ca}^{+2}$, Fura-2 exhibits an absorption shift from 380 to $340 \mathrm{~nm}$ of excitation. Thus, the relative $\mathrm{Ca}^{+2}$ concentration was evaluated based on the fluorescence ratio after dual-wavelength excitation. Upon calcium exposure, the $\triangle p m c A$ mutant strain had an increased relative level of intracellular calcium concentration compared to the same strain in the absence of calcium (Figure 8). This difference is not observed for the wild-type, $\triangle p m c B$ and complemented strains, and alcA::pmc $C$ strain (data not shown).

We have not observed any differential susceptibility of these mutants to antifungal agents, such as amphotericin, azoles, and caspofungin, in E-tests (data not shown). These results indicate $p m c A$ and $p m c B$ are involved in calcium and manganese metabolism in $A$. fumigatus, and also suggest $p m c A$ is the major transporter responsible for removing calcium from the cytoplasm. 
A

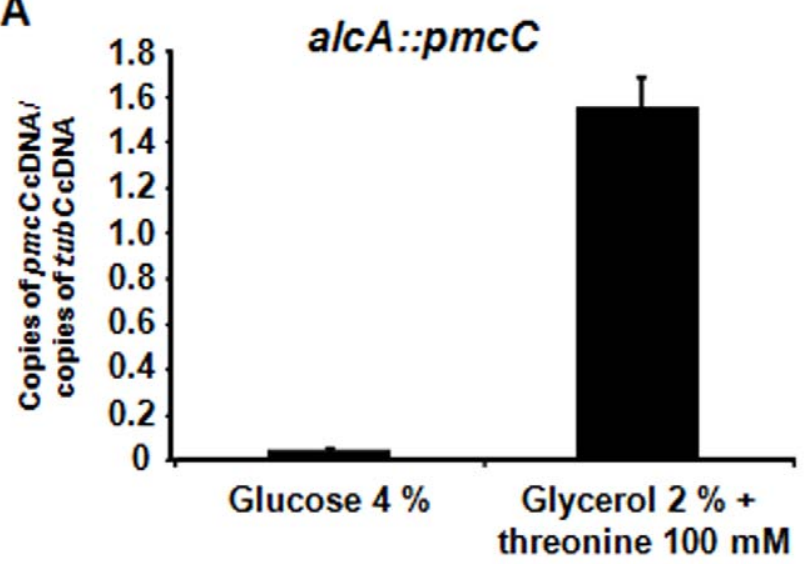

B

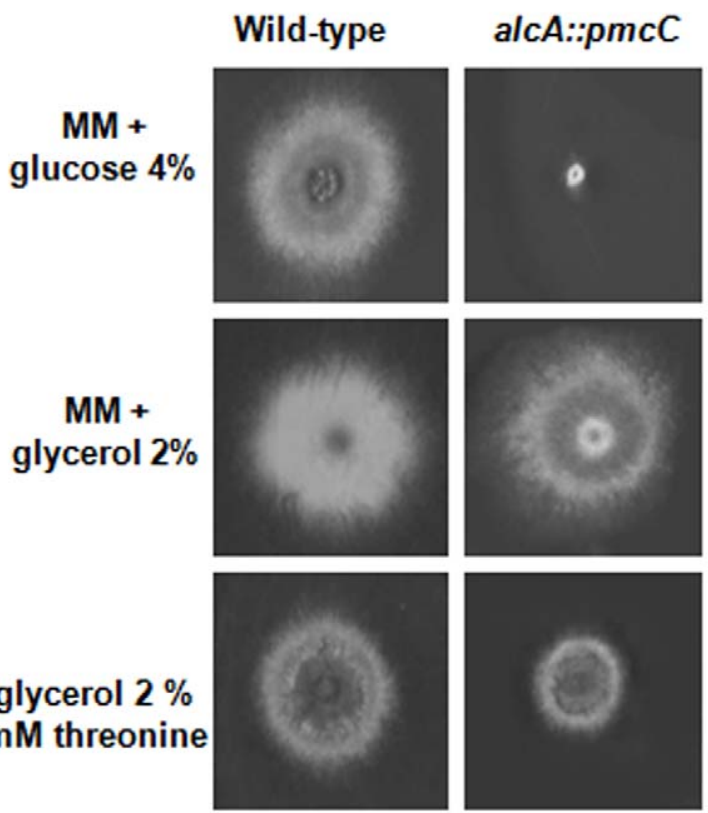

Figure 3. The pmcC gene is an essential $A$. fumigatus gene. (A) The alcA::pmcC strain was grown for 16 hours in $\mathrm{MM}+2 \%$ glycerol at $37^{\circ} \mathrm{C}$ and transferred into either $\mathrm{MM}+4 \%$ glucose or $\mathrm{MM}+2 \%$ glycerol +threonine $100 \mathrm{mM}$ and grown for further 6 hours. The relative quantitation of pmcC and tubulin gene expression was determined by a standard curve (i.e., $\mathrm{C}_{\mathrm{T}}$-values plotted against a logarithm of the DNA copy number). The results are the means ( \pm standard deviation) of four biological replicates. (B) Growth phenotypes of the alcA::pmcC mutant strain. The $A$. fumigatus wild-type and alcA::pmcC mutant strains were grown for 72 hours at $37^{\circ} \mathrm{C}$ in $\mathrm{MM}+4 \%$ glucose, $\mathrm{MM}+2 \%$ glycerol and $\mathrm{MM}+2 \%$ glycerol +threonine $100 \mathrm{mM}$. doi:10.1371/journal.pone.0037591.g003

Expression of the pmcA-C genes in murine-infecting $A$. fumigatus wild-type, $\triangle c a l A$ and $\triangle c r z A$ mutant strains

Previously, we generated by RNA amplification multiple gene expression profiles via minute samplings of $A$. fumigatus germlings during the initiation of murine infection $[25,26]$. This enabled us to identify genes preferentially expressed during adaptation to the mammalian host niche. Here, we took advantage of the establishment of this technical platform to characterize genes that have in vivo decreased or increased mRNA abundance in the $\triangle$ calA and $\triangle c z A$ mutant strains when compared to the wild-type strain.
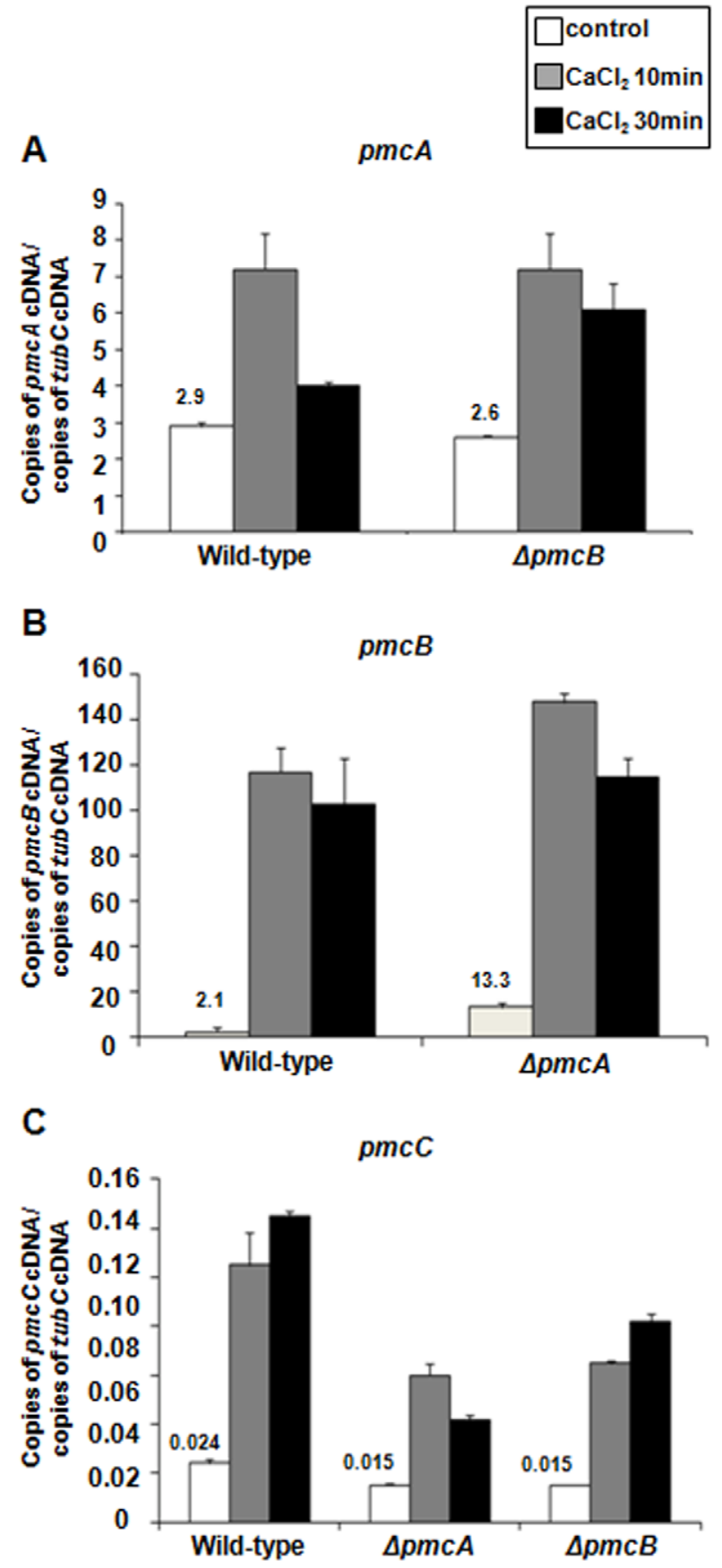

Figure 4. The $p m c A-C$ genes have increased mRNA abundance when exposed to calcium. The absolute quantitation of $p m c A, p m c B$, and $p m c C$ and tubulin gene expression was determined by a standard curve (i.e., $C_{T}$-values plotted against a logarithm of the DNA copy number). The results are the means ( \pm standard deviation) of four biological replicates. (A-C) The mRNA abundance of pmcA-C in the wildtype, $\triangle p m c A$, and $\triangle p m c B$.

doi:10.1371/journal.pone.0037591.g004

We firstly characterized the time course of hyphal development in the sequenced clinical isolate Af293, $\triangle$ calA and $\triangle$ crzA mutant strains by histopathological examination of infected neutropenic murine lung tissues (Supplementary Figure S4). Lung sections collected and formalin-fixed at 4, 10 and 14 hours post-infection contained numerous $A$. fumigatus wild-type, $\triangle$ calA and $\triangle c r z A$ spores in close association with murine epithelium in the bronchioles and 
A

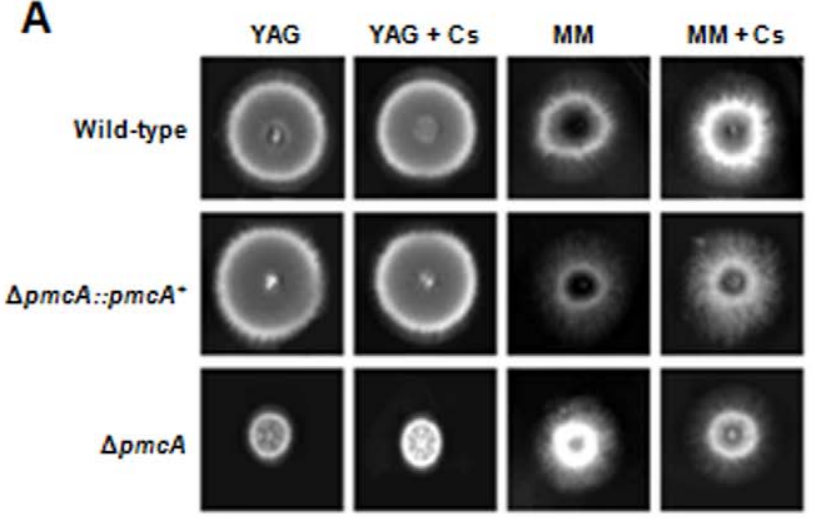

B
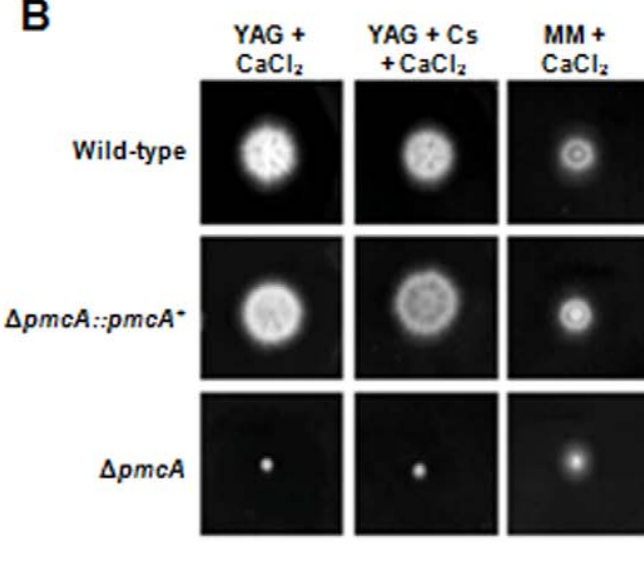

$M M+C s$ $+\mathrm{CaCl}_{2}$
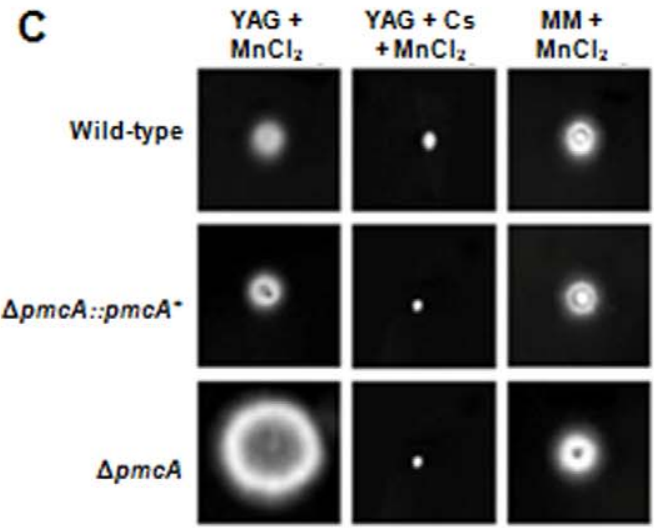

$\mathrm{MM}+\mathrm{Cs}$ $+\mathrm{MnCl}_{2}$
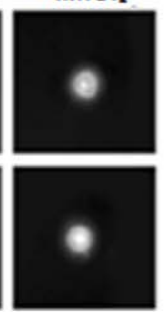

Figure 5. Growth phenotypes of the $\triangle p m c A$ mutant strain. The A. fumigatus wild-type, $\triangle p m c A:: p m c A^{+}$and $\triangle p m c A$ mutant strains were grown for 72 hours at $37^{\circ} \mathrm{C}$ in (A)YAG, YAG $+25 \mathrm{ng} / \mathrm{ml}$ cyclosporin (Cs), $\mathrm{MM}$, or $\mathrm{MM}+25 \mathrm{ng} / \mathrm{ml} \mathrm{Cs}$; (B) $\mathrm{YAG}+500 \mathrm{mM} \mathrm{CaCl}, \mathrm{YAG}+25 \mathrm{ng} / \mathrm{ml}$ $\mathrm{Cs}+500 \mathrm{mM} \mathrm{CaCl}, \mathrm{MM}+500 \mathrm{mM} \mathrm{CaCl}$, or $\mathrm{MM}+25 \mathrm{ng} / \mathrm{ml} \mathrm{Cs}+500 \mathrm{mM}$ $\mathrm{CaCl}_{2} ;$ (C) $\mathrm{YAG}+25 \mathrm{mM} \mathrm{MnCl}, \mathrm{YAG}+25 \mathrm{ng} / \mathrm{ml} \mathrm{Cs}+25 \mathrm{mM} \mathrm{MnCl}$, $\mathrm{MM}+25 \mathrm{mM} \mathrm{MnCl}$, or $\mathrm{MM}+25 \mathrm{ng} / \mathrm{ml} \mathrm{Cs}+25 \mathrm{mM} \mathrm{MnCl}$.

doi:10.1371/journal.pone.0037591.g005

alveoli (Supplementary Figure S4, upper panels). At 12-14 hours post-infection, $80 \%$ of $A$. fumigatus conidia from the three strains had undergone comparable germination and primary hyphal production. Bronchoalveolar lavage was performed immediately using pre-warmed sterile saline and samples (BALFs) were snap frozen prior to RNA extraction and amplification. Within
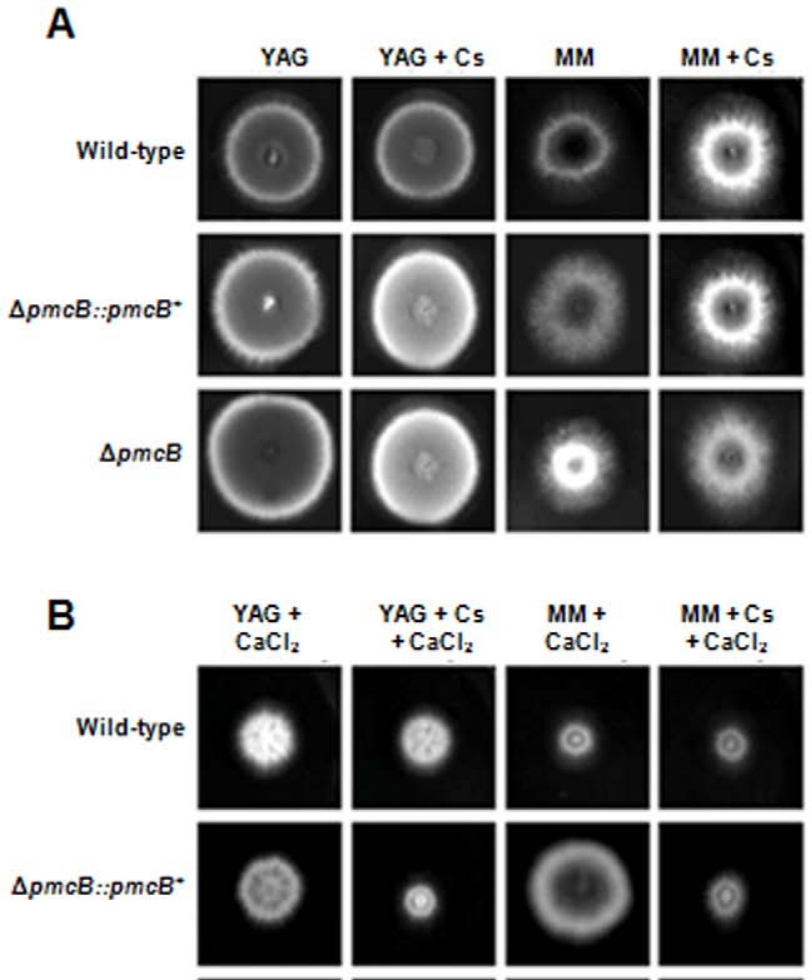

$\Delta p m c B$
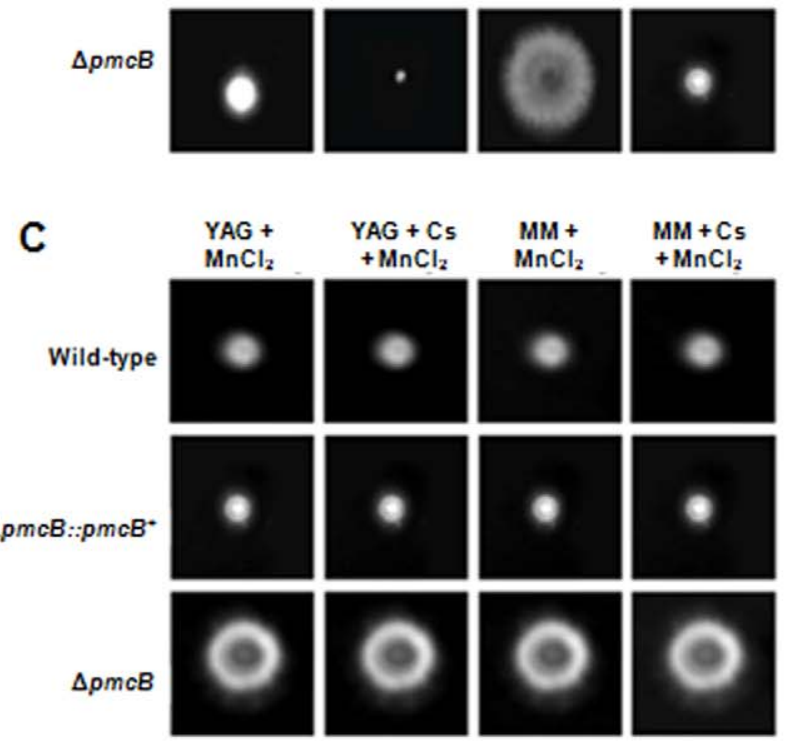

$\mathrm{MM}+\mathrm{Cs}$

$+\mathrm{MnCl}_{2}$

Figure 6. Growth phenotypes of the $A p m c B$ mutant strain. The $A$. fumigatus wild-type, $\triangle p m c B:: p m c B$ and $\triangle p m c B$ mutant strains were grown for 72 hours at $37^{\circ} \mathrm{C}$ in (A)YAG, YAG $+25 \mathrm{ng} / \mathrm{ml}$ cyclosporin (Cs), $\mathrm{MM}$, or $\mathrm{MM}+25 \mathrm{ng} / \mathrm{ml} \mathrm{Cs}$; (B) $\mathrm{YAG}+500 \mathrm{mM} \mathrm{CaCl}, \mathrm{YAG}+25 \mathrm{ng} / \mathrm{ml}$ $\mathrm{Cs}+500 \mathrm{mM} \mathrm{CaCl} 2, \mathrm{MM}+500 \mathrm{mM} \mathrm{CaCl}$, or $\mathrm{MM}+25 \mathrm{ng} / \mathrm{ml} \mathrm{Cs}+500 \mathrm{mM}$ $\mathrm{CaCl}_{2}$; (C) YAG+25 mM MnCl $2, Y A G+25 \mathrm{ng} / \mathrm{ml} \mathrm{Cs+25} \mathrm{mM} \mathrm{MnCl}_{2}$, $\mathrm{MM}+25 \mathrm{mM} \mathrm{MnCl}$, or $\mathrm{MM}+25 \mathrm{ng} / \mathrm{ml} \mathrm{Cs}+25 \mathrm{mM} \mathrm{MnCl}$. doi:10.1371/journal.pone.0037591.g006

infection groups BALFs were pooled prior to RNA extraction and mRNA amplification. Total RNA extracted from these cultures was used to amplify fluorescent-labeled cDNAs for real-time PCR experiments. We designed Lux fluorescent probes and used realtime RT-PGR analysis to quantify the $p m c A, p m c B$, and $p m c C$ mRNA abundance in the $\triangle$ calA and $\triangle$ crzA germlings after bronchoalveolar lavage at 4 and 14 hours growth and compared this with their expression in the wild-type strain grown during the 
A

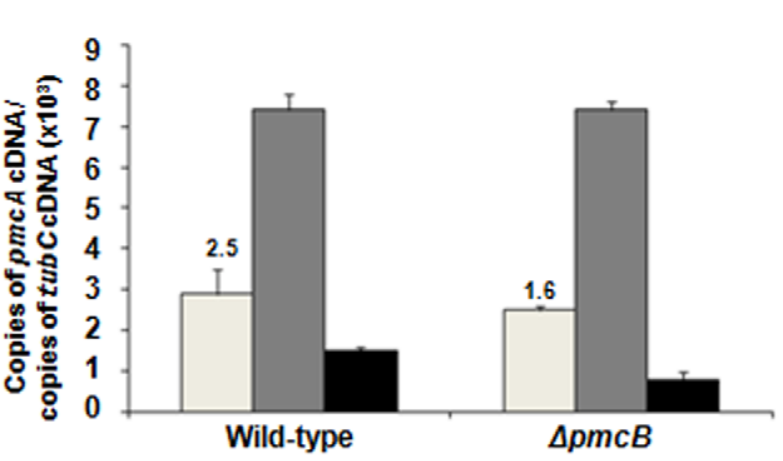

B

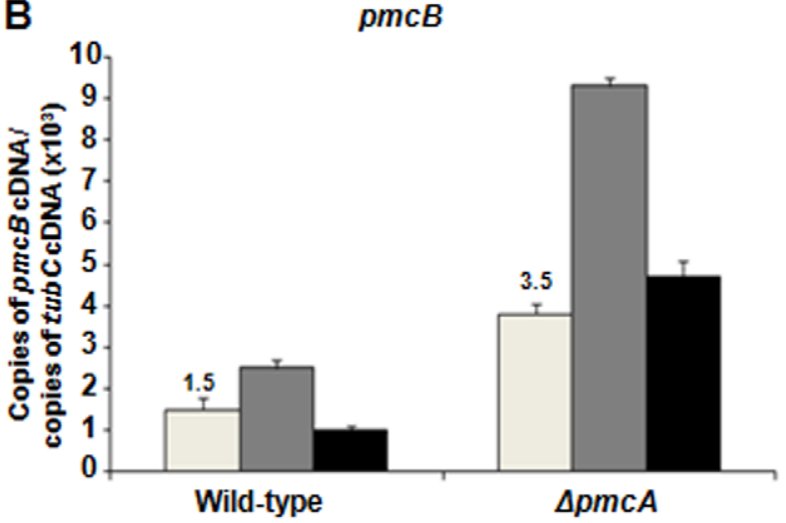

C

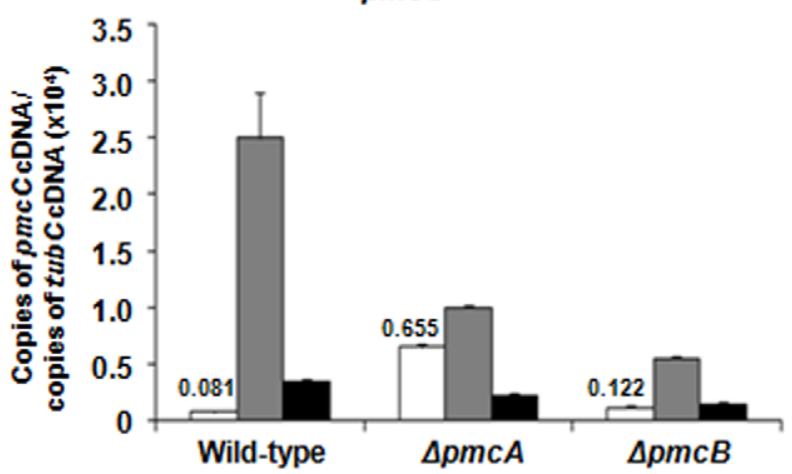

Figure 7. The pmcA- $C$ genes have increased mRNA abundance when exposed to manganese. The absolute quantitation of $p m c A$, $p m c B$, and $p m c C$ and tubulin gene expression was determined by a standard curve (i.e., $C_{T}$-values plotted against a logarithm of the DNA copy number). The results are the means ( \pm standard deviation) of four biological replicates. (A-C) The mRNA abundance of $p m c A-C$ in the wildtype, $\triangle p m c A$, and $\triangle p m c B$.

doi:10.1371/journal.pone.0037591.g007

same time points (reference treatment) (Table 1). All these three genes showed, to different extents, decreased mRNA abundance during the initiation of murine infection by the A. fumigatus $\triangle$ calA and $\triangle$ crz $A$ mutant strains relative to the wild-type strain. Thus, it seems that in vivo pmcA-C mRNA accumulation is dependent on CalA and crzA.
The $A$. fumigatus $\triangle p m c A$ mutant strain is avirulent in low dose murine infection

To assess the role of PmcA-B in pathogenicity we tested the $A$. fumigatus $\triangle p m c A-B$ mutant strains in a neutropenic murine model of invasive pulmonary aspergillosis, comparing virulence of the $A$. fumigatus $\triangle p m c A-B$ mutant strains $(\mathrm{n}=10$ for each mutant) to that of the wild-type $(n=10)$ (Figure 9A and Supplementary Figure S5). While infection with the wild-type strain resulted in a mortality rate of over $100 \%$ at 6 days post-infection, infection with the pmcA deletion strain resulted in a significantly reduced mortality rate of approximately $20 \%$ after 10 days post-infection $(\mathrm{p}<0.005)$. The pmcB mutant showed virulence comparable to the wild-type strain (Supplementary Figure S5). Since the comparison between $\Delta p m c A$ infected group and the non-infected group (PBS) showed to be statistically non-significant $(p=0.1451)$, we can consider this strain avirulent. To directly link the observed attenuated virulence of the $\triangle p m c A$ mutant with the replacement of the $\triangle p m c A$ locus we tested an independent strain resulting from single ectopic reintegration of the wild-type $\triangle p m c A$ locus (Supplementary Figure S6) and with the complementation strain full virulence was restored (Figure 9A). To further understand the basis of attenuated virulence in the $\triangle p m c A$ background we made histopathological examinations of infected tissues at early time points in infection, aiming to identify differences in growth rate, tissue invasion and inflammatory responses between the two strains. At 72 hours post-infection the lungs of mice infected with the wild-type isolate contained multiple foci of invasive hyphal growth, manifesting as both penetration of the pulmonary epithelium in major airways (Figure 9B) and pockets of branched invading mycelia originating from the alveoli (Figure 9B). In contrast, infection resulting from $\triangle p m c A$ inoculations was typified by contained inflammatory infiltrates in bronchioles (Figure 9B) some of which contained fungal elements in the form of poorly germinated or ungerminated spores. Fungal burden data as measured by real-time PCR showed that the $\triangle p m c A$ mutant strain did not grow within the lungs as well as the wild-type and the complemented $\triangle p m c A$ strains (Figure 9C, $p<0.0001)$. Taken together, these data strongly indicate that PmcA plays a role in $A$. fumigatus virulence.

\section{Discussion}

We have been actively looking for additional components of the $\mathrm{Ca}^{+2}$-calcineurin pathway $[14,17,27]$. One of these components, the transcription factor CrzA induces the expression of various cation transporters that act at the plasma membrane or on other membranous organelles [14,17]. Very little is known about calcium transport and calcium homeostasis in filamentous fungi. Most of our knowledge about calcium homeostasis in fungi is derived from $S$. cerevisiae, where more than $95 \%$ of cellular calcium is sequestered in the vacuole $[28,29,30]$. In $S$. cerevisiae PMC1, PMR1, and VCX1 encode a vacuolar $\mathrm{Ca}^{2+}$ ATPase involved in depleting cytosol of $\mathrm{Ca}^{2+}$ ions, a high affinity $\mathrm{Ca}^{2+} / \mathrm{Mn}^{2+}$ P-type ATPase required for $\mathrm{Ca}^{2+}$ and $\mathrm{Mn}^{2+}$ transport into the Golgi, and a vacuolar membrane antiporter with $\mathrm{Ca}^{2+} / \mathrm{H}^{+}$and $\mathrm{K}^{+} / \mathrm{H}^{+}$ exchange activity, involved in the control of cytosolic $\mathrm{Ca}^{2+}$ and $\mathrm{K}^{+}$ concentrations, respectively $[19,22,31]$. S. cerevisiae PMC1 knockout mutants sequester $\mathrm{Ca}^{+2}$ into the vacuole at $20 \%$ of the wildtype levels and fail to grow in media containing high levels of $\mathrm{Ca}^{+2}$ [19]. Mutations in the calcineurin A or B subunits or the addition of FK506 or cyclosporin A restored growth of pmc1 mutants in media with high $\mathrm{Ca}^{+2}$ concentrations $[20,21]$. In Neurospora crassa it was reported that active transport across the plasma membrane is important for keeping low levels of cytosolic calcium [32,33]. In addition, in this species the vacuole is important for regulating the 


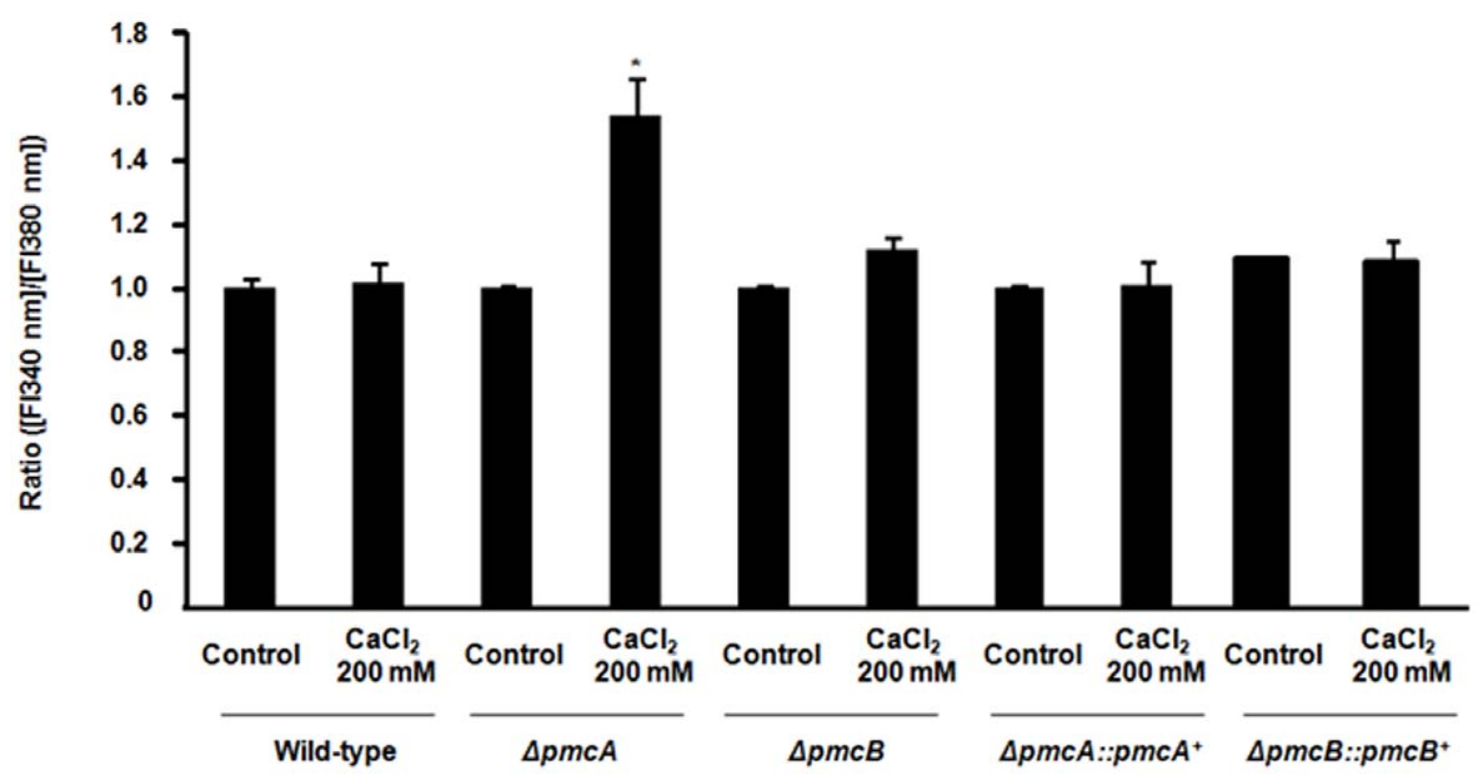

Figure 8. The $\triangle P m c A$ mutant strain has increased accumulation of calcium in the cytoplasm. The relative levels of intracellular calcium in the wild-type, $\triangle p m c A$ and $\triangle p m c B$ mutant strains were determined using the calcium-sensitive dye Fura-2-AM. The relative $\mathrm{Ca}^{+2}$ concentration was determined based on the fluorescence ratio after dual-wavelength excitation (fluorescent intensity at $340 \mathrm{~nm}$ [FI340 nm]/[FI380 nm]. Data shown are means of three repetitions \pm standard deviations. Statistical analysis was performed by using either One-Way Anova with Newman-Keuls post-tests or Tukey's multiple comparison tests. ${ }^{*} p<0.005$.

doi:10.1371/journal.pone.0037591.g008

intracellular calcium levels $[32,34,35]$. In $\mathcal{N}$. crassa, there are two PMC1 homologues, $\mathcal{N C A}-2$ and $\mathcal{N C A}-3$ [36]. The $\mathcal{N} C A-2$ fused with GFP is located in the plasma membrane as well as in vacuolar membranes in this organism [37], suggesting $N C A-2$ functions to pump calcium out of the cell. The $\Delta n c a-3$ strain showed comparable levels of calcium sensitivity to the wild-type strain; in contrast, $\Delta$ nca-2 showed significant inhibition of growth at $50 \mathrm{mM} \mathrm{CaCl}_{2}$ and accumulates 10 -fold more intracellular calcium than the wild-type strain [36]. In $A$. nidulans, two null mutants constructed for the PMC1 homologues, $p m c A$ and $p m c B$, displayed low-sensitivity to $700 \mathrm{mM} \mathrm{CaCl}{ }_{2}$ concentrations [38]. However, the double $A$ nidulans $\triangle p m c A \triangle p m c B$ mutant has increased calciumsensitivity suggesting these two genes are genetically interacting [38].

Rispail et al. [39] have proposed that A. fumigatus has three $P M C 1$, two PMR1, and four VCX1 homologues. Here, we have concentrated our attention on three genes encoding PMC1 calcium transporter homologues that have their mRNA levels dependent on CalA-CrzA [14,17], generated mutants of them, and studied their phenotypes and virulence. Although A. fumigatus pmcA-C genes are involved in calcium metabolism, this work did not provide a full characterization of their function. We do not know their sub-cellular localization and how they affect subcellular calcium abundance. We were not able to knock-out $p m c C$ and subsequently demonstrated that $p m c C$ is an essential $A$. fumigatus gene by constructing a conditional $p m c C$ mutant. The pmc $C$ downregulation causes growth inhibition and its overexpression can produce a physiological imbalance, as the mutant strain also has reduced growth. We were able to demonstrate that CrzA can control the pmcA-C mRNA expression by binding directly to their promoter regions. Crzlp has a $\mathrm{C} 2 \mathrm{H} 2$ zinc finger motif that binds to CDRE in the promoters of genes that are regulated by calcineurin and calcium (Stathopoulos and Cyert, 1997). Yoshimoto et al. [40] have identified the S. cerevisiae Crzlp-binding site as
5'-GNGGC(G/T)CA-3' by in vitro site selection. Recently, Hagiwara et al. [41] identified and characterized the $A$. nidulans AncrzA gene. They performed an in silico analysis by also using MEME of the possible presence of a CDRE-like consensus motif in the promoter regions of 25 AnCrzA-dependent genes. By analyzing their promoter regions, 5'-G[T/G]GGC[T/A]G[T/ G] G-3' was presumed to be the consensus sequence for the $A$. nidulans AnCrzA-dependent genes. By using a combination of MEME analysis and the $A$. nidulans CDRE consensus as a guide, we were able to identify $28 \mathrm{~A}$. fumigatus genes that were repressed in $\triangle$ crzA mutant strain upon $\mathrm{CaCl}_{2}$ exposure (Soriani et al., 2010), with $5^{\prime}$-GT $[\mathrm{T} / \mathrm{G}] \mathrm{G}[\mathrm{G} / \mathrm{C}][\mathrm{T} / \mathrm{A}] \mathrm{GA}[\mathrm{G} / \mathrm{T}]-3^{\prime}$ as the CDREconsensus sequence for A. fumigatus AfCrzA-dependent genes. Here, we demonstrated that CrzA can bind directly to 300-bp upstream regions from $p m c A-C$ genes. In two of these genes, $p m c A$ and $p m c C$, we were able to identify putative CDRE motifs and demonstrated that they can completely inhibited the complexes formed with $p m c A$ and $p m c C$ DNA fragments. These results strongly suggest these CDRE motifs are functional and this is probably the first demonstration of CDRE functionality in a human pathogenic fungus.

Cyclosporin was able to modulate the sensitivity or resistance of these mutants to either calcium or manganese chloride, once more supporting the interaction between calcineurin and the function of these transporters. In addition, we showed wild-type levels of susceptibility to amphotericin B, voriconazole, posoconazole, itraconazole, and caspofungin (E-test assays) and that there were no defects in cell wall integrity (data not shown). We also observed that the complete and minimal culture media affected the susceptibility of the $\triangle p m c A$ and $\triangle p m c B$ mutant strains to calcium and manganese chloride. The defined macronutrients composition of MM medium could explain the differences in growth of the $\triangle p m c A$ and $\triangle p m c B$ mutant strains in YAG and MM media. The $\mathrm{MM}$ is composed of glucose, trace elements, and macronutrients 
Table 1. Real-time RT-PCR for pmcA-C genes from the in vivo microarray.

\begin{tabular}{|c|c|c|c|c|c|c|}
\hline Gene ${ }^{*}$ & $\begin{array}{l}\text { Wild-type } \\
4 \text { hs }\end{array}$ & $\begin{array}{l}\text { Wild-type } \\
14 \text { hs }\end{array}$ & $\begin{array}{l}\triangle \text { CalA } \\
4 \text { hs }\end{array}$ & $\begin{array}{l}\triangle \text { CalA } \\
14 \mathrm{hs}\end{array}$ & $\begin{array}{l}\triangle c r z A \\
4 \mathrm{hs}\end{array}$ & $\begin{array}{l}\triangle c r z A \\
14 \mathrm{hs}\end{array}$ \\
\hline $\begin{array}{l}p m c A \\
\text { (Afu1g10880) }\end{array}$ & $0.38 \pm 0.01$ & $0.22 \pm 0.00$ & $0.20 \pm 0.00$ & $0.09 \pm 0.00$ & $0.17 \pm 0.01$ & $0.11 \pm 0.00$ \\
\hline $\begin{array}{l}p m c B \\
\text { (Afu3g10690) }\end{array}$ & $1.52 \pm 0.02$ & $3.46 \pm 0.23$ & $0.23 \pm 0.00$ & $0.32 \pm 0.06$ & $0.35 \pm 0.08$ & $0.56 \pm 0.00$ \\
\hline $\begin{array}{l}\text { pmcC } \\
\text { (Afu7g01030) }\end{array}$ & $0.01 \pm 0.00$ & $0.01 \pm 0.00$ & $0.00 \pm 0.00$ & $0.00 \pm 0.00$ & $0.00 \pm 0.00$ & $0.00 \pm 0.00$ \\
\hline
\end{tabular}

*The mRNA abundance of $A$. fumigatus pmcA-C genes during growth in lung alveoli. Real-time RT-PCR was used to quantify mRNA abundance. The measured quantity of mRNA for a specific gene in each of the treated samples was normalized using the $C_{T}$ values obtained for the $\beta$-tubulin mRNA amplifications run on the same plate. The relative quantitation of a specific gene and $\beta$-tubulin gene expression was determined by a standard curve (i.e., $C_{T}-$ values plotted against a logarithm of the DNA copy number). The results of four sets of experiments were combined for each determination; means \pm standard deviation are shown. The values represent the cDNA concentration of a specific gene divided by the $\beta$-tubulin cDNA concentration. doi:10.1371/journal.pone.0037591.t001

(salt solution). The salt solution is composed of sodium nitrate, potassium chloride, potassium phosphate, and magnesium sulphate. When the wild-type, $\triangle p m c A$, and $\triangle p m c B$ strains are grown in MM supplemented only with a single one of these macronutrients, there is a reduction in radial growth for all strains, except for $\mathrm{MM}+\mathrm{MgSO}_{4}$ that showed about the same radial growth as in MM (data not shown). The most likely reasons for this outcome are either the mechanism of action of these transporters depends on other cations, such as sodium, or there is some cross-talk with the mechanisms for ion detoxification. Recently, Spielvogel et al. [42] have shown that SltA, a transcription factor important for cation adaptation and homeostasis acts positively on the transcription of the Enalp-like $\mathrm{Na}^{+}$pump gene enaA and negatively on the transcription of the putative vacuolar $\mathrm{Ca}^{+2} / \mathrm{H}^{+}$ exchanger gene $v c x A$ (A. fumigatus homologue is Afulg04270). Interestingly, the negative regulation of $v c x A$ by SltA is opposed by its transcriptional activation by CrzA [42].

A. fumigatus pmc $A-C$ genes have decreased mRNA abundance into the alveoli in the $\triangle$ calA and $\triangle \mathrm{cr} z A$ mutant strains. Accordingly, when $A$. fumigatus is exposed in vitro to calcium chloride, there is a decrease in pmcA-C mRNA abundance in both mutants. When we compare the absolute $p m c A-C$ mRNA abundance levels in the wildtype strain grown in mouse alveoli, we observed that $p m c B$ has about five to ten times higher levels than $p m c A$, while $p m c C$ has very low levels of mRNA abundance (1,000 to 3,000 times lower than $p m c B)$. Consistently, the same mRNA abundance is observed when $A$. fumigatus is exposed in vitro to calcium chloride. Interestingly, there is an increase in the $p m c B$ mRNA levels in the $\triangle p m c A$ mutant strain when this strain is not exposed to $\mathrm{CaCl}_{2}$, suggesting a compensation for the $p m c A$ absence. An intriguing observation from our work is the fact that $p m c C$ has very low absolute levels of mRNA accumulation in all conditions tested in this work, but it is an essential gene. This is confirmed by a weak CrzA binding to pmc $C$ promoter. It is possible that PmcC specific activity is very high and this will compensate its low mRNA levels. It is also possible that PmcC has other functions that were not identified in this work and are essential for cell metabolism. Interestingly, both $\triangle p m c A$ and $\triangle p m c B$ mutants are more resistant to $\mathrm{MnCl}_{2}$ than the wild-type strain and had reduced $p m c C$ mRNA accumulation when exposed to either $\mathrm{CaCl}_{2}$ or $\mathrm{MnCl}_{2}$. These results suggest pmc $C$ mRNA levels are dependent on $p m c A$ and $p m c B$, when $A$. fumigatus is exposed either to calcium or manganese. However, this effect is more notable in the presence of manganese.

The $\triangle p m c A$ mutant is avirulent in a neutropenic murine model of invasive pulmonary aspergillosis. The reduced virulence of the $\triangle p m c A$ could be due to an excess of calcium in the cytoplasm that could not be removed due to the lack of $p m c A$, thus potentially affecting several functions such as secretion, cell wall composition and the activation of pathways necessary for infection. Interestingly, we did not observe attenuated virulence for $\triangle p m c B$, suggesting that the different PMC1 paralogues have different functions during pathogenicity. This is the first demonstration of the involvement of a calcium transporter in $A$. fumigatus virulence. Previously, Pinchai et al. [16] have shown that A.fumigatus $\Delta p m r A$ has several defects related to growth, cationic tolerance, and increased beta-glucan and chitin content, but in spite of all these abnormal phenotypes the mutant strain remained virulent.

In conclusion, we have shown that PmcA is required for full virulence in animal infection. In addition, that PmcA acts in the $A$. fumigatus $\mathrm{Ca}^{+2}$-calcineurin signaling pathway and influences the relative intracellular calcium concentration. Further studies are necessary to address the sub-cellular location of PmcA, -B, and - C, and how PmcA contributes to the pathogenesis of aspergillosis.

\section{Materials and Methods}

\section{Ethics statement}

The principles that guide our studies are based on the Declaration of Animal Rights ratified by the UNESCO in January 27,1978 in its articles $8^{\text {th }}$ and $14^{\text {th }}$. All protocols used in this study were approved by the local ethics committee for animal experiments from the Campus of Ribeirão Preto from Universidade de Sao Paulo (Permit Number: 08.1.1277.53.6; studies on the interaction of Aspergillus fumigatus with animals). All animals used in this study were housed in groups of five in individually ventilated cages and were cared for in strict accordance to the principles outlined in the by the Brazilian College of Animal Experimentation (Princípios Éticos na Experimentação Animal - Colégio Brasileiro de Experimentação Animal, COBEA) and Guiding Principles for Research Involving Animals and Human Beings, American Physiological Society. All efforts were made to minimize suffering. Animals were clinically monitored at least twice daily by a veterinarian and humanely sacrificed if moribund (defined by lethargy, dyspnoea, hypothermia and weight loss).

\section{Strains and culture conditions}

The A. fumigatus strains used in this study are CEA17 (pyrG $G^{-}$), Af293 (wild-type), $\triangle$ calA and $\Delta$ crzA (Soriani et al., 2008), CEA17-80 (as the wild-type in all the experiments), $\triangle p m c A$ ( $\triangle p m c A:: p y r G$ ), $\triangle p m c B$ ( $\triangle p m c B:: p y r G), \quad \Delta v c x A(\Delta v c x A:: p y r G) . \quad \Delta p m c A:: p m c A^{+}$and alcA::pmc $C$. The media used were of two basic types, i.e. complete and minimal. The complete media comprised the following three 
A

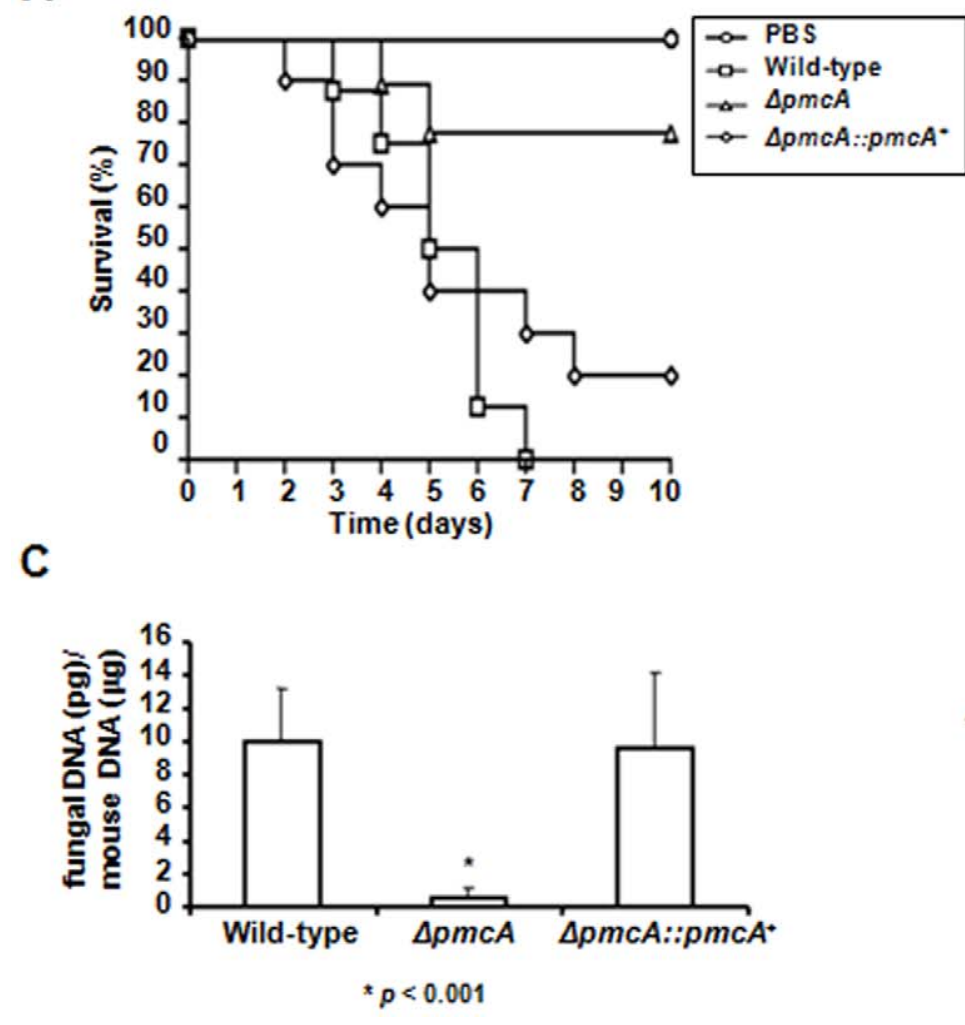

B

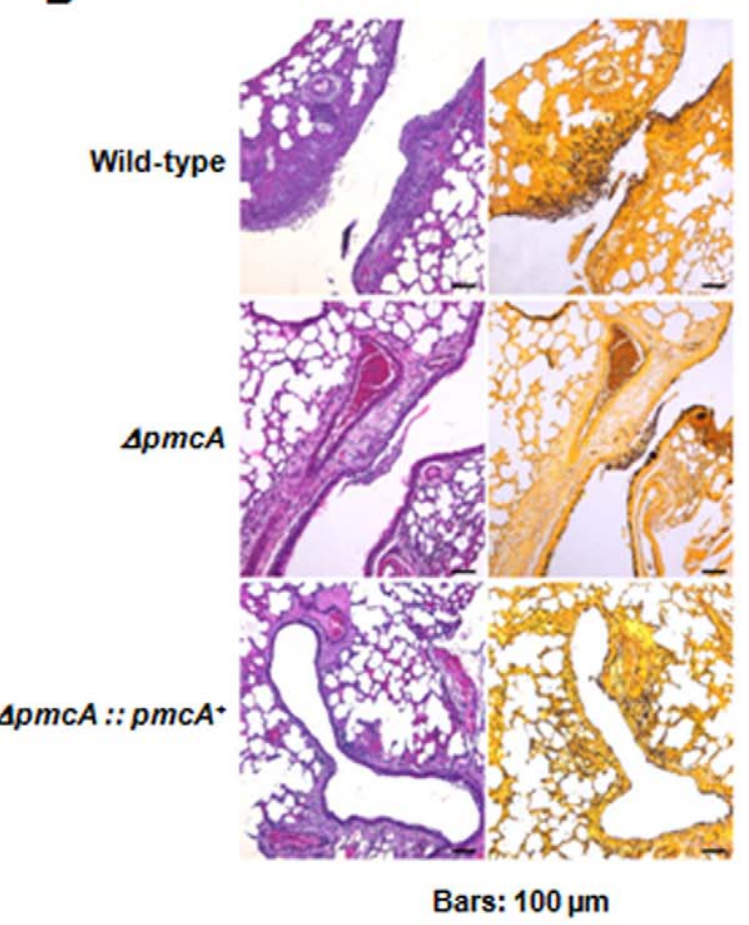

Figure 9. $\boldsymbol{A}$. fumigatus pmcA contributes to virulence in neutropenic mice. (A) Comparative analysis of wild-type, $\triangle p m c A$ and $\triangle p m c A:: p m c A^{+}$ strains in a neutropenic murine model of pulmonary aspergillosis. A group of 10 mice per strain was infected intranasally with a $20 \mu \mathrm{l}$ suspension of conidiospores at a dose of $5.0 \times 10^{4}$. (B) Histological analysis of infected murine lung were performed 72 hours after infection with the wild-type strain reveals invasion of the murine lung epithelium (C) Fungal burden was determined 48 hours post-infection by real-time RT-PCR based on $18 S$ rRNA gene of $A$. fumigatus and an intronic region of the mouse GAPDH gene. Fungal and mouse DNA quantities were obtained from the $\mathrm{Ct}$ values from an appropriate standard curve. Fungal burden was determined through the ratio between ng of fungal DNA and $\mu \mathrm{g}$ of mouse DNA quantities. The results are the means ( \pm standard deviation) of five lungs for each treatment. doi:10.1371/journal.pone.0037591.g009

variants: YAG $(2 \% \mathrm{w} / \mathrm{v}$ glucose, $0.5 \% \mathrm{w} / \mathrm{v}$ yeast extract, $2 \% \mathrm{w} / \mathrm{v}$ agar, trace elements), YUU [YAG supplemented with $1.2 \mathrm{~g} \mathrm{l}$ l-1 (each) of uracil and uridine], and liquid YG or YG + UU medium with the same composition (but without agar). A modified minimal medium (MM: 1\% glucose, original high nitrate salts, trace elements, $2 \%$ agar, $\mathrm{pH} 6.5$ ) was also used. Expression of $p m c C$ gene, under the control of alcA promoter, was regulated by carbon source: repression on glucose $4 \% \mathrm{w} / \mathrm{v}$, derepression on glycerol, and induction on threonine. Therefore, $\mathrm{MM}+$ Glycerol and MM + Threonine were identical to MM, except that glycerol (2\% v/v) and/or threonine $(100 \mathrm{mM})$ were added, respectively, in place of glucose as the sole carbon source. Trace elements, vitamins, and nitrate salts were included as described by [43]. Strains were grown at $37^{\circ} \mathrm{C}$ unless indicated otherwise. Additionally, $10 \%$ fetal bovine serum (Gibco) was used as a medium.

\section{Construction of the A. fumigatus mutants}

A gene replacement cassette was constructed by "in vivo" recombination in $S$. cerevisiae as previously described [44]. Briefly, approximately $2.0 \mathrm{~kb}$ regions on either side of each ORF were selected for primer design. For construction, the primers were named as $5 \mathrm{~F}$ and $5 \mathrm{R}$, were used to amplify the $5^{\prime}$-UTR flanking region of the targeted ORF. Likewise, the primers $3 \mathrm{~F}$ and $3 \mathrm{R}$ were used to amplify the 3 '-UTR ORF flanking region, and the primers $5 \mathrm{~F}$ and $3 \mathrm{R}$ also contains a short homologue sequence to the MCS of the plasmid pRS426. Both fragments, 5- and 3-UTR, were PCR-amplified from A. fumigatus genomic DNA (gDNA). The pyrG used in the $A$. fumigatus cassette for generating the mutant strains were used as marker for prototrophy. Deletion cassette generation was achieved by transforming each fragment along with the plasmid pRS426 BamHI/EcoRI cut in the in S. cerevisiae strain SC94721 by the lithium acetate method [45]. The DNA of the yeast transformants was extracted by the method described by Goldman et al. [46], dialysed and transformed by electroporation in Escherichia coli strain DH10B to rescue the pRS426 plasmid harboring the cassette. The cassette was PCR-amplified from these plasmids and used for A. fumigatus transformation. Southern blot analyses were used throughout of the manuscript to demonstrate that the transformation cassettes had integrated homologously at the targeted $A$. fumigatus loci. For the construction of the alcA::pmc $C$ strain, $1000 \mathrm{bp}$ of the $p m c C$ encoding region was cloned downstream to the alcA promoter into the pMCB17apx vector. This construction was further transformed in A. fumigatus to replace the endogenous $p m c C$ promoter yielding the strain alcA::pmcC. The $\triangle p m c A$ mutant strain was complemented by co-transforming a $p m c A^{+}$DNA fragment (approximately $1 \mathrm{~kb}$ from each $5^{\prime}$ and $3^{\prime}-$ flanking regions plus the ORF) together with the $\mathrm{pHAT} \alpha$ vector [47] and selecting for hygromycin resistance in MM plates with $150 \mu \mathrm{g} / \mathrm{ml}$ of hygromycin B. 


\section{RNA extraction and real-time $P C R$ reactions}

After treatment conditions, mycelia were harvested by filtration, washed twice with $\mathrm{H}_{2} \mathrm{O}$ and immediately frozen in liquid nitrogen. For total RNA isolation, the germlings were disrupted by grinding in liquid nitrogen with pestle and mortar. Total RNA was extracted with Trizol reagent (Invitrogen, USA). Ten micrograms of RNA from each treatment was then fractionated in $2.2 \mathrm{M}$ formaldehyde, $1.2 \% \mathrm{w} / \mathrm{v}$ agarose gel, stained with ethidium bromide, and then visualized under UV light. The presence of intact 25S and 18S ribosomal RNA bands was used to assess the integrity of the RNA. RNasefree DNase I treatment, for the realtime PGR experiments, was carried out as previously described [48]. Twenty micrograms of total RNA was treated with DNase, purified using a RNAeasy kit (Qiagen) and cDNA was generated using the SuperScript III First Strand Synthesis system (Invitrogen) with oligo(dT) primers, according to the manufacturer's protocol.

All the PCR reactions were performed using an ABI 7500 Fast Real-Time PCR System (Applied Biosystems, USA) and Taq-Man Universal PCR Master Mix kit (Applied Biosystems, USA). The reactions and calculations were performed according to Semighini et al. [48]. The primers and Lux ${ }^{\mathrm{TM}}$ fluorescent probes (Invitrogen, USA) used in this work are described in Supplementary Table S1.

\section{Cloning the crzA gene into the PDEST15 vector}

The Gateway Technology (Invitrogen) was used to construct, in Escherichia coli, the expression system consisting of the CRZA gene $\mathrm{N}$-tagged to the GST gene. Briefly, the coding region of the exon 2 from CrzA was amplified from the cDNA sample by PCR using Platinum $^{\circledR}$ Taq DNA Polymerase High Fidelity. (Invitrogen) and specific primers (CRZ-exon2-attB1-F 5' - GGGGACAAGTTGTACAAAAAAGCAGGGTTCGAAGGAGATAGAAC-

CATGTCCCGCGGGCGTAGCAAG-3' and CRZ-attB2-R 5'GGGGACCACTTTGTACAAGAAAGCTGGGTCTCAATA-

GAAGTTACGGGCAGCAG-3'). Amplification was run for 30 cycles consisting of denaturation at $94^{\circ} \mathrm{C}$ for $1 \mathrm{~min}$, primer annealing at $55^{\circ} \mathrm{C}$ for $1 \mathrm{~min}$ and primer extension at $68^{\circ} \mathrm{C}$ for $2 \mathrm{~min}$. The PCR product carrying the attB sites was purified from agarose gel using the QIAquick PCR purification kit (Qiagen) and cloned into the pDONR201 plasmid (Invitrogen) using the BP Clonase. The BP clonase catalyze the in vitro recombination of PCR products or DNA segments from clones (containing attB sites) and a donor vector (containing attP sites) to generate entry clones. The entry clone pDONR201-CrzA was transformed into E. coli DH10B competent cells and selected for kanamicyn resistence. Entry clones were checked by sequencing using the ATT primers (ATT1F- 5'- TGGGGTTAACGCTAGCATGGATCTC-3' and ATT2 R- 5'- GTAACATCAGAGATTTTGAGACAC-3') and further used in LR reactions (Invitrogen) with the vector pDEST15 (an N-terminal GST fusion vector containing the T7 promoter) to generate the expression vector pDEST15GST/CrzA.

\section{Production and Purification of GST::CrzA}

A. nidulans CrzA was expressed as a GST-fusion protein from the construct pDEST15-GST/CrzA in E. coli Rosetta ${ }^{\text {TM }}$ (DE3) pLysS strain (Novagen). Cells harboring the plasmid construction were grown in $1 \mathrm{~L}$ of LB medium to an O.D.600 nm of 0.8 and protein expression was induced at $12^{\circ} \mathrm{C}, 180 \mathrm{rpm}$ overnight with $0.4 \mathrm{mM}$ IPTG final concentration. After induction, cells were harvested by centrifugation, suspended in phosphate-buffered saline solution $\left(500 \mathrm{mM} \mathrm{NaCl}, 2.7 \mathrm{mM} \mathrm{KCl}, 100 \mathrm{mM} \mathrm{Na}_{2} \mathrm{HPO}_{4}\right.$, $2 \mathrm{mM}$ KH2PO4, 5\% v/v glycerol, $0.5 \% \quad \mathrm{NP}-40, \quad \mathrm{pH} 7.4)$ containing $10 \mathrm{mM}$ benzamidine, $0.5 \mathrm{mM}$ EDTA and $2 \mathrm{mM}$ of each DTT and PMSF and lysed by sonication (ten $30 \mathrm{sec}$ pulses on ice) in a Vibra-Cell disrupter $\left(\right.$ Sonics $\left.{ }^{\circledR}\right)$. Cell lysate was clarified at $23,000 \times g, 20 \mathrm{~min}, 4^{\circ} \mathrm{C}$, and the recombinant protein was purified by affinity chromatography on a GSTrap FF column (GE HealthCare) according to manufacturer's instructions on an ÄKTA Prime purification system. Recombinant protein was eluted in a linear gradient of $20 \mathrm{mM}$ glutathione in $50 \mathrm{mM}$ Tris-HCl, $500 \mathrm{mM} \mathrm{NaCl,} \mathrm{5 \%} \mathrm{v/v} \mathrm{glycerol,} 2$ mM DTT, pH 8.0 buffer. Chromatographic fractions were analyzed by SDS-PAGE followed by Coomassie Brilliant Blue staining [49] and fractions containing the purified protein were combined, concentrated and quantified using BSA as standard [50].

\section{Electrophoretic Mobility Shift Assay}

GST::CrzA recombinant protein was assayed in DNA-protein binding reactions using three $300 \mathrm{bp}$ DNA fragments of the $p m c A$, $p m c B$ and $p m c C$ promoters as probes, containing the putative cisregulatory calcineurin-dependent response elements (CDREs) for the transcription factor CrzA (Supplementary Table S1 and Figure $\mathrm{S} 1)$. Binding reactions were carried out in $1 \times$ binding buffer (25 mM HEPES- KOH, pH 7.9, $20 \mathrm{mM} \mathrm{KCl,} \mathrm{10 \%} \mathrm{w/v} \mathrm{glycerol,}$ 1 mM DTT, 0.2 mM EDTA, pH 8.0, 0.5 mM PMSF, $12.5 \mathrm{mM}$ benzamidine, $5 \mathrm{mg} / \mathrm{mL}$ of each antipain and pepstatin $\mathrm{A}$ ) containing $2 \mu \mathrm{g}$ poly $(\mathrm{dI}-\mathrm{dC}) .(\mathrm{dI}-\mathrm{dC})$ as non-specific competitor and $1-2 \mu \mathrm{g}$ of GST::CrzA recombinant protein, at room temperature for $10 \mathrm{~min}$. After that, DNA probes $\left(10^{4} \mathrm{cpm}\right)$ were added and the binding reactions were incubated at room temperature during $20 \mathrm{~min}$ prior to being loaded onto a native $5 \%$ polyacrylamide gel in $0.5 \times \mathrm{TBE}$ buffer. Gels were run at $10 \mathrm{~mA}, 15^{\circ} \mathrm{C}$, dried, and exposed to X-ray film. For competition assays, a molar excess of the specific DNA competitors were added prior to incubation with the radiolabeled probe.

\section{DNA Probes and Specific Competitors for EMSA}

Putative cis CrzA motifs were visually identified in the promoter regions of the genes $p m c A, p m c B$ and $p m c C$ by using the $A$. fumigatus CDRE consensus. To produce the $p m c A$ probe, a 300 bp DNA fragment of the $p m c A$ promoter was amplified from $A$. fumigatus genomic DNA by using the primers PMCA-5R and 5'-PMCA (Supplementary Table S1) in the presence of $\left[\alpha-{ }^{32} \mathrm{P}\right]$-dATP $(3,000 \mathrm{Ci} / \mathrm{mmol})$ and purified on $2 \%$ low-melting point agarose gel. $p m c B$ and $p m c C$ probes were prepared as above using the primer pairs PMCB-5R and 5'-PMCB (Supplementary Table S1), and PMCG-5R and 5'-PMCG (Supplementary Table S1). The unlabeled $300 \mathrm{bp} p m c A, p m c B$ and $p m c C$ probes were used as specific DNA competitors which were quantified by measuring the absorbance at $260 \mathrm{~nm}$ and added to the binding reaction in a 30to 50 -fold molar excess, $10 \mathrm{~min}$ prior to the addition of the respective probes. DNA oligonucleotides containing the CDRE motifs identified in $p m c A$ and $p m c C$ probes were also used as specific competitors after annealing the complementary oligonucleotides pairs pmcA1/pmcA2 and pmcG1/pmcC2, respectively (Supplementary Table S1). The DNA oligonucleotides were quantified by measuring the absorbance at $260 \mathrm{~nm}$ and added to the reaction in 10-30 fold molar excess.

Mutated probes $(\mathrm{m} p m c A$ and $\mathrm{mpmc} C$ ) were prepared by changing the element core sequences by site-directed mutagenesis in a two-step PCR. In the mpmcA probe the sequence $5^{\prime}$ CGCTGCCCC-3' was changed to 5'-AAAGTAAAA-3' by using the oligonucleotide pair mPMCA-F and mPMCA-R in the in the first reaction to amplify two fragments. The oligonucleotide pair PMCA-5R and 5'-PMCA (Supplementary Table S1) was used in a second reaction to amplify the whole DNA fragment containing the mutation. In the mpmc $C$ probe the sequence $5^{\prime}$-CACAGGCAC-3' was changed to 5'-ACACTAACA-3' by using the 
oligonucleotide pair mPMCC-F and $\mathrm{mPMCG}-\mathrm{R}$ in the in the first reaction. The oligonucleotide pair PMCG-5R and 5'-PMCG (Supplementary Table S1) was used in a second reaction to amplify the whole DNA fragment containing the mutation. For EMSA, both mutated fragments were used as templates in PCR amplifications in the presence of $\left[\alpha^{32} \mathrm{P}\right]$-dATP $(3,000 \mathrm{Ci} / \mathrm{mmol})$ and purified on $2 \%$ low-melting point agarose gel.

\section{Determination of the relative levels of intracellular calcium concentration}

To investigate the relative intracellular free calcium concentration we used the Fura-2 acetoxymethyl ester (Fura-2-AM; Invitrogen). Briefly, $10^{7}$ conidia of each wild-type, $\triangle p m c A$, $\triangle p m c A:: p m c A^{+}, \triangle p m c B$, and $\triangle p m c B:: p m c B^{+}$were incubated in $\mathrm{YG}$ medium for 8 hours with shaking at $37^{\circ} \mathrm{C}$. Then, each strain was either treated with $500 \mathrm{mM} \mathrm{CaCl}$, or not, in fresh YG medium for 30 minutes. After incubation the cells were washed three times with PBS and loaded with $10 \mu \mathrm{M}$ Fura-2-AM for $30 \mathrm{~min}$ at $37^{\circ} \mathrm{C}$. After washing, Fura-2 fluorescence was measured by alternating the excitation wavelengths at 340 and $380 \mathrm{~nm}$ with an emission wavelength fixed at $505 \mathrm{~nm}$. The relative intracellular calcium concentration is expressed as the ratio between fluorescence intensities with excitation wavelengths at 340 and $380 \mathrm{~nm}$. All data presented are representative of three independent experiments.

\section{Murine model of pulmonary aspergillosis}

Outbred female mice (BALB/c strain, 20-22 g) were housed in individually vented cages, containing 5 animals. Mice were immunosuppressed with cyclophosphamide at $150 \mathrm{mg} / \mathrm{kg}$ of body weight, administered intraperitoneally on days $-4,-1$ and 2, and hydrocortisonacetate was injected subcutaneously at $200 \mathrm{mg} / \mathrm{kg}$ on day -3 , modified from [51]. A. fumigatus spores for inoculation were grown on Aspergillus complete medium for 2 days prior to infection. Conidia were freshly harvested using sterile PBS and filtered through Miracloth (Calbiochem). Conidial suspensions were spun for $5 \mathrm{~min}$ at $3000 \mathrm{~g}$, washed three times with sterile PBS, counted using a hemocytometer and re-suspended at a concentration of $2.5 \times 10^{6}$ conidia/ml. Viable counts from administered inocula were determined following serial dilution by plating on Aspergillus complete medium and grown at $37^{\circ} \mathrm{C}$. Mice were anaesthetized by halothane inhalation and infected by intranasal instillation of $5.0 \times 10^{4}$ conidia in $20 \mu \mathrm{l}$ of PBS. As negative control, a group of 5 mice received only PBS intranasally. Mice were weighed every $24 \mathrm{~h}$ from the day of infection and visually inspected twice daily. In the majority of cases the endpoint for survival experimentation was when a $20 \%$ reduction in body weight measured from the day of infection and at this point the mice were sacrificed. Significance of comparative survival was calculated using Log Rank analysis in the Prism statistical analysis package. Additionally, at 3 days post infection, 2 mice per strain were sacrificed, from which the lungs were removed, fixed and processed for histological analysis.

\section{Lung histopathology and fungal burden}

After sacrifice, the lungs were removed and fixed for $24 \mathrm{~h}$ in $10 \%$ buffered formalin phosphate. Samples were washed in $70 \%$ alcohol several times, dehydrated in alcohols of increasing concentrations, diafanized in xylol and embedded in paraffin. For each sample, sequential $5 \mu \mathrm{m}$ sections were collected on glass slides and the sections were stained with Gomori methenamine silver (GMS) or hematoxylin and eosin (HE) stain following standard protocols [24]. Briefly, sections were deparaffinized, oxidized with $4 \%$ chromic acid, stained with methenamine silver solution, and counter stained with picric acid or light green. For HE staining, sections were deparaffinized, stained first with hematoxylin and then stained with eosin. All stained slides were immediately washed, preserved with mounting medium and sealed with a cover glass. Microscopical analyses were done using an Axioplan 2 imaging microscope (Zeiss) at the stated magnifications under brightfield conditions.

To investigate fungal burden in murine lungs, mice were immunosuppressed with cyclophosphamide at $150 \mathrm{mg} / \mathrm{kg}$ of body weight administred intraperitoneally on days -4 and -1 and hydrocortisonacetat injected subcutaneously at $200 \mathrm{mg} / \mathrm{kg}$ on day -3 . Five mice per group (wild-type, $\triangle p m c A, \triangle p m c A:: p m c A$, and PBS control) were inoculated with $5 \times 10^{5}$ conidia/20 $\mu$ l suspension intranasally. A higher inoculum, in comparison to the survival experiments, was used to increase fungal DNA detection. Animals were sacrificed 48 hours post infection, both lungs were harvested and immediately frozen in liquid nitrogen. A mortar and pestle were used to pulverize the samples (frozen in liquid nitrogen) and DNA was extracted by the Phenol/Chlroform method. DNA quantity and quality was assessed with a NanoDrop 2000 (Thermo Scientific). Around $200 \mathrm{ng}$ of total DNA of each sample was used for quantitative Real-Time PCR reaction. A primer and a Lux ${ }^{\mathrm{TM}}$ probe (invitrogen) were used to amplify the 18S rRNA region of $A$. fumigatus (primer: 5'-CTTAAATAGCGCGGTCGGCATT-3', probe: 5'-CATCACAGACGTGT TATTGCGG-3') and an intronic region of mouse GAPDH (primer: 5'-CGAGGGACTTGGAGGACACAG-3', probe: 5'-GGGCAAGGCTAAAGGTCAGCG-3'). Six-point standard curves were calculated using serial dilutions of gDNA from all $A$. fumigatus strains used here and non-infected mouse lung. Fungal and mouse DNA quantities were obtained from the Ct values from an appropriate standard curve. Fungal burden was determined via the ratio between ng of fungal and mouse DNA.

\section{Bronchoalveolar lavages}

To analyze gene expression of $A$. fumigatus strains during early pulmonary infection, Outbred female mice (BALB/c strain, 20$22 \mathrm{~g}$ ) were housed in individually vented cages, containing 5 animals. Mice were immunosuppressed with cyclophosphamide (Genuxal, Baxter) at $150 \mathrm{mg} / \mathrm{kg}$ of body weight administered intraperitoneally on days -4 and -1 and hydrocortisone sodium succinate (Hidrosone, Cellofarm) was injected subcutaneously at $200 \mathrm{mg} / \mathrm{kg}$ on day -1 . All mice received tetracycline hydrochloride $0.5 \mathrm{mg} / \mathrm{L}$ in drinking water, as prophylaxis against bacterial infection. A. fumigatus spores for inoculation were grown on Aspergillus complete solid medium (YAG) for 2 days prior to infection. Conidia were freshly harvested using sterile PBS and filtered through Miracloth (Calbiochem). Conidial suspensions were spun for $5 \mathrm{~min}$ at 4,000 rpm, washed three times with sterile PBS, counted using a hemocytometer and re-suspended at a concentration of $2.5 \times 10^{10}$ conidia/ml. Five mice per group (wildtype, $\triangle$ crz $A$ and $\triangle$ calA) were anesthetized by isoflurane (Isothane, Baxter) inhalation and infected by intranasal instillation of $10^{9}$ conidia in $40 \mu \mathrm{l}$ of PBS. Groups of infected mice were sacrificed and processed collectively at time points 4 and 12 hours postinfection. Bronchoalveolar lavage (BAL) was performed immediately after culling using three $0.5 \mathrm{ml}$ aliquots of cold sterile PBS. To remove the mice cells from BALs, samples were spun down in microcentrifuge tubes, supernatants were removed, the samples were resuspended in $1 \mathrm{ml}$ of sterile ultrapure water, centrifuged again and finally the pellets were snap frozen immediately using liquid nitrogen. To extract RNA, BAL samples from each strain (5 BALs per strain) were mixed with $1 \mathrm{ml}$ Trizol LS Reagent 
(Invitrogen) and acid treated glass beads (425-600 $\mu \mathrm{m}$, SigmaAldrich). Fungal cells were homogenized by 10 min vortexing, centrifuged at 12,000 rpm for $10 \mathrm{~min}$, the upper phase was mixed with $200 \mu \mathrm{l}$ chloroform, centrifuged again, the new upper phase was mixed with $500 \mu \mathrm{l}$ isopropanol and incubated overnight at $-80^{\circ} \mathrm{C}$. After washing the pellet with $70 \%$ ethanol, RNA was dissolved in $20 \mu \mathrm{l}$ DEPG water. Further RNA purification was carried out using RNeasy mini kit (Qiagen), following manufacturer's instructions. RNA concentration and integrity was monitored by NanoDrop ${ }^{\circledR} 2000$ - Thermo Scientific (Uniscience). RNA amplification was done according to Agilent Low RNA Input Fluorescent Linear Amplification kit (Agilent Technologies). RNAse free DNAse treatment was carried out as previously described [48].

\section{Supporting Information}

Figure S1 (A) Clustal alignment of A. fumigatus PmcA, PmcB, and PmcC.

(DOCX)

Figure S2 (B) CrzA-binding regions of the $p m c A-C$ genes (upstream the ATG start codon). Underline and in bold the putative CDRE-motif.

(DOCX)

Figure S3 Southern blot and PCR analyses for (A) $\Delta v c x A,(\mathrm{~B})$ $\triangle p m c B,(\mathrm{C}) \triangle p m c A$ and $(\mathrm{D})$ alcA::pmcC.

(PPT)

\section{References}

1. Fox DS, Heitman J (2002) Good fungi gone bad: the corruption of calcineurin. Bioessays 24: 894-903.

2. Cyert MS (2003) Calcineurin signaling in Saccharomyces cerevisiae: how yeast go crazy in response to stress. Biochem Biophys Res Commun 311: 1143-1150.

3. Steinbach WJ, Reedy JL, Cramer RA, Perfect Jr. JR, Heitman J (2007) Harnessing calcineurin as a novel anti-infective agent against invasive fungal infections. Nat Rev Microbiol 5: 418-430.

4. Stie J, Fox D (2008) Calcineurin regulation in fungi and beyond. Eukaryot Cell 7: $177-186$.

5. Stathopoulos-Gerontides A, GuoJJ, Cyert MS (1999) Yeast calcineurin regulates nuclear localization of the Crzlp transcription factor through dephosphorylation. Genes Dev 13: 798-803.

6. Karababa M, Valentino E, Pardini G, Coste AT, Bille J, et al. (2006) CRZ1, a target of the calcineurin pathway in Candida albicans. Mol Microbiol 59: 1429-1451.

7. Stathopoulos AM, Cyert MS (1997) Calcineurin acts through the GRZ1/TCN1encoded transcription factor to regulate gene expression in yeast. Genes Dev 11: 3432-3445.

8. Zakrzewska A, Boorsma A, Brul S, Hellinngwerf KJ, Klis FM (2005) Transcriptional response of Saccharomyces cerevisiae to the plasma membraneperturbing compound chitosan. Eukaryot Cell 4: 703-715.

9. Matheos DP, Kingsbury TJ, Ahsan US, Cunningham KW (1997) Tcnlp/ Crzlp, a calcineurin-dependent transcription factor that differentially regulates gene expression in Saccharomyces cerevisiae. Genes Dev 11: 3445-3458.

10. Hirayama S, Sugiura R, Lu Y, Maeda T, Kawagishi K, et al. (2003) Zinc finger protein Przl regulates $\mathrm{Ca}^{+2}$ but not $\mathrm{Cl}^{-}$homeostasis in fission yeast. $\mathrm{J}$ Biol Chem 20: 18078-18084.

11. Onyewu C, Wormley FL, Perfect Jr. JR, Heitman J (2004) The calcineurin target, Crz1, functions in azole tolerance but is not required for virulence of Candida albicans. Infect Immun 72: 7330-7333.

12. Santos M, de Larrinoa IF (2005) Functional characterization of the Candida albicans $C R Z 1$ gene encoding a calcineurin-regulated transcription factor. Curr Genet 48: 88-100

13. Da Silva Ferreira ME, Heinekamp T, Hartl A, Brakhage AA, Semighini CP, et al. (2007) Functional characterization of the Aspergillus fumigatus calcineurin. Fungal Genet Biol 44: 219-230.

14. Soriani FM, Malavazi I, da Silva Ferreira ME, Savoldi M, von Zeska Kress MR, et al. (2008) Functional characterization of the Aspergillus fumigatus CRZ1 homologue, CrzA. Mol Microbiol 67: 1274-1291.

15. Cramer RAJ, Perfect BZ, Pinchai N, Park S, Perlin DS, et al. (2008) Calcineurin target $c r z A$ regulates conidial germination, hyphal growth, and pathogenesis of Aspergillus fumigatus. Eukaryot Cell 7: 1085-1097.
Figure S4 Histological analysis of alveolar lavages after infection with the $A$. fumigatus wild type, $\triangle$ calA, and $\Delta c r z A$ strains. Germlings and host cells were detected by using Grocotts methenamine silver and haematoxylin and eosin staining, respectively. Bars, $100 \mu \mathrm{m}$. (PPTX)

Figure S5 A. fumigatus $\triangle p m c B$ virulence studies in neutropenic mice. Comparative analysis of wild type and $\triangle p m c B$ strains in a neutropenic murine model of pulmonary aspergillosis. A group of 10 mice per strain was infected intranasally with $20 \mu \mathrm{l}$ suspension of conidiospores at a dose of $2.0-5.0 \times 10^{4}$.

(PPTX)

Figure S6 (A) Growth phenotype of the $\triangle p m c A:: p m c A^{+}$strain grown on $\mathrm{YAG}+\mathrm{CaCl}_{2} 500 \mathrm{mM}$. (B) $\mathrm{PCR}$ of the $p m c A$ open reading frame. $(\mathrm{C}) \mathrm{PCR}$ of the $p m c B$ open reading frame.

(PPT)

Table S1 List of primers and probes used in this work. (DOC)

\section{Acknowledgments}

We would like to thank Dr. Andréa Carla Quiapim and the LBMPFFCLRP/USP for DNA sequencing. We also thank the reviewers for their suggestions and comments.

\section{Author Contributions}

Conceived and designed the experiments: GHG MCB. Performed the experiments: TMD FZF RSA TFR LNZR MS. Analyzed the data: GHG MHSG MCB. Wrote the paper: GHG NAB.

16. Pinchai N, Juvvadi PR, Fortwendel JR, Perfect BZ, Rogg LE, et al. (2010) The Aspergillus fumigatus P-type Golgi apparatus $\mathrm{Ca} 2+/ \mathrm{Mn} 2+$ ATPase PmrA is involved in cation homeostasis and cell wall integrity but is not essential for pathogenesis. Eukaryot Cell 9: 472-6.

17. Soriani FM, Malavazi I, Savoldi M, Espeso E, Dinamarco TM, et al. (2010) Identification of possible targets of the Aspergillus fumigatus CRZ1 homologue, CrzA. BMC Microbiol 10: 12.

18. Pittman JK (2011) Vacuolar Ca(2+) uptake. Cell Calcium 50: 139-146.

19. Cunningham KW, Fink GR (1994) Calcineurin-dependent growth control in Saccharomyces cerevisiae mutants lacking PMC1, a homolog of plasma membrane $\mathrm{Ca}^{2+}$ ATPases. J Cell Biol 124: 351-63.

20. Cunningham KW (2011) Acidic calcium stores of Saccharomyces cerevisiae. Cell Calcium 50: 129-38.

21. Cunningham KW, Fink GR (1996) Calcineurin inhibits VCX1-dependent $\mathrm{H}^{+}$/ $\mathrm{Ca}^{2+}$ exchange and induces $\mathrm{Ca}^{2+}$ ATPases in Saccharomyces cerevisiae. Mol Cell Biol 16: 2226-2237.

22. Olivero I, Corbacho I, Hernández LM (2003) The ldb1 mutant of Saccharomyces cerevisiae is defective in Pmrlp, the yeast secretory pathway/Golgi $\mathrm{Ca}\left({ }^{2+}\right) / \mathrm{Mn}\left({ }^{2+}\right)$ ATPase. FEMS Microbiol Lett 219: 137-42.

23. Flipphi M, Kocialkowska J, Felenbok B (2002) Characteristics of physiological inducers of the ethanol utilization (alc) pathway in Aspergillus nidulans. Biochem J 15: 25-31.

24. Greenberger PA (2002) Allergic bronchopulmonary aspergillosis. J Allergy Clin Immunol 110: 685-92.

25. McDonagh A, Fedorova ND, Crabtree J, Yu Y, Kim S, et al. (2008) Subtelomere directed gene expression during initiation of invasive aspergillosis. PLoS Pathog 4: e1000154.

26. Cairns T, Minuzzi F, Bignell E (2010) The host-infecting fungal transcriptome. FEMS Microbiol Lett 307: 1-11.

27. Malavazi I, da Silva Ferreira ME, Soriani FM, Dinamarco TM, Savoldi M, et al. (2009) Phenotypic analysis of genes whose mRNA accumulation is dependent on calcineurin in Aspergillus fumigatus. Fungal Genet Biol 46: 791-802.

28. Dunn T, Gable K, Beeler T (1994) Regulation of cellular $\mathrm{Ca}^{+2}$ by yeast vacuoles. J Biol Chem 269: 7273-7278.

29. Eilam Y, Lavi H, Grossowicz N (1985) Cytoplasmic $\mathrm{Ca}^{+2}$ - homeostasis maintained by a vacuolar $\mathrm{Ca}^{+2}$ transport-system in the yeast Saccharomyces cerevisiae. J Gen Microbiol 131: 623-629.

30. Halachmi D, Eilam Y (1989) Cytosolic and vacuolar $\mathrm{Ca}^{+2}$ - concentrations in yeast cells measured with the $\mathrm{Ca}^{+2}$-sensitive fluorescence dye indo-1. FEBS Lett 256: 55-61.

31. Pozos TC, Sekler I, Cyert MS (1996) The product of HUM1, a novel yeast gene, is required for vacuolar $\mathrm{Ca}^{2+} / \mathrm{H}^{+}$exchange and is related to mammalian $\mathrm{Na}^{+}$/ $\mathrm{Ca}^{2+}$ exchangers. Mol Cell Biol 16: 3730-3741. 
32. Miller AJ, Vogg G, Sanders D (1990) Cytosolic calcium homeostasis in fungi: roles of plasma membrane transport and intracellular sequestration of calcium. Proc Natl Acad Sci U S A 87: 9348-9352.

33. Stroobant P, Scarborough GA (1979) Active transport of calcium in Neurospora plasma membrane vesicles. Proc Natl Acad Sci U S A 76: 3102-3106.

34. Cornelius G, Nakashima H (1987) Vacuoles play a decisive role in calcium homeostasis in Neurospora crassa. J Gen Microbiol 133: 2341-2347.

35. Cramer CL, Davis RH (1984) Polyphosphate-cation interaction in the amino acid-containing vacuole of Neurospora crassa. J Biol Chem 259: 5152-5157.

36. Bowman BJ, Draskovic M, Freitag M, Bowman EJ (2009) Structure and distribution of organelles and cellular location of calcium transporters in Neurospora crassa. Eukaryot Cell 8: 1845-1855.

37. Bowman BJ, Abreu S, Margolles-Clark E, Draskovic M, Bowman EJ (2011) Role of four calcium transport proteins, encoded by nca-1, nca-2, nca-3, and cax, in maintaining intracellular calcium levels in Neurospora crassa. Eukaryot Cell 10: $654-661$.

38. Findon H, Calcagno-Pizarelli AM, Martínez JL, Spielvogel A, MarkinaIñarrairaegui A, et al. (2010) Analysis of a novel calcium auxotrophy in Aspergillus nidulans. Fungal Genet Biol 47: 647-655.

39. Rispail N, Soanes DM, Ant C, Czajkowski R, Grünler A, et al. (2009) Comparative genomics of MAP kinase and calcium-calcineurin signalling components in plant and human pathogenic fungi. Fungal Genet Biol 46: 287-98.

40. Yoshimoto H, Saltsman K, Gasch AP, Li HX, Ogawa N, et al. (2002) Genomewide analysis of gene expression regulated by the calcineurin/Crzlp signaling pathway in Saccharomyces cerevisiae. J Biol Chem 277: 31079-31088.

41. Hagiwara D, Kondo A, Fujioka T, Abe K (2008) Functional analysis of C2H2 zinc finger transcription factor CrzA involved in calcium signaling in Aspergillus nidulans. Curr Genet 54: 325-338.
42. Spielvogel A, Findon H, Arst HN, Araújo-Bazán L, Hernández-Ortíz P, et al. (2008) Two zinc finger transcription factors, CrzA and SltA, are involved in cation homoeostasis and detoxification in Aspergillus nidulans. Biochem J 414: 419-29.

43. Kafer E (1977) Meiotic and mitotic recombination in Aspergillus and its chromosomal aberrations. Adv Genet 19: 33-131.

44. Colot HV, Park G, Turner GE, Ringelberg C, Crew CM, et al. (2006) A highthroughput gene knockout procedure for Neurospora reveals functions for multiple transcription factors. Proc Natl Acad Sci USA 103: 10352-10357.

45. Schiestl RH, Gietz RD (1989) High efficiency transformation of intact yeast cells using single stranded nucleic acids as a carrier. Curr Genet 16: 339-346.

46. Goldman GH, dos Reis Marques E, Duarte Ribeiro DC, de Souza Bernardes LA, Quiapin AC, et al. (2003) Expressed sequence tag analysis of the human pathogen Paracoccidioides brasiliensis yeast phase: identification of putative homologues of Candida albicans virulence and pathogenicity genes. Eukaryot Cell 2: 34-48.

47. Herrera-Estrella A, Goldman GH, Van Montagu M (1990) High-efficiency transformation system for the biocontrol agents, Trichoderma spp. Mol Microbiol 4: $839-43$.

48. Semighini CP, Marins M, Goldman MHS, Goldman GH (2002) Quantitative analysis of the relative transcript levels of ABC transporter Atr genes in Aspergillus nidulans by Real-Time Reverse Transcripition-PCR assay. Appl Environ Microbiol 68: 1351-1357.

49. Laemmli UK (1970) Cleavage of structural proteins during the assembly of the head of bacteriophage T4. Nature 227: 680-685.

50. Hartree EF (1972) Determination of protein: a modification of the Lowry method that gives a linear photometric response. Anal Biochem 48: 422-427.

51. Mota Júnior AO, Malavazi I, Soriani FM, Heinekamp T, Jacobsen I, et al. (2008) Molecular characterization of the Aspergillus fumigatus NCS-1 homologue, NcsA. Mol Genet Genomics 280: 483-95. 